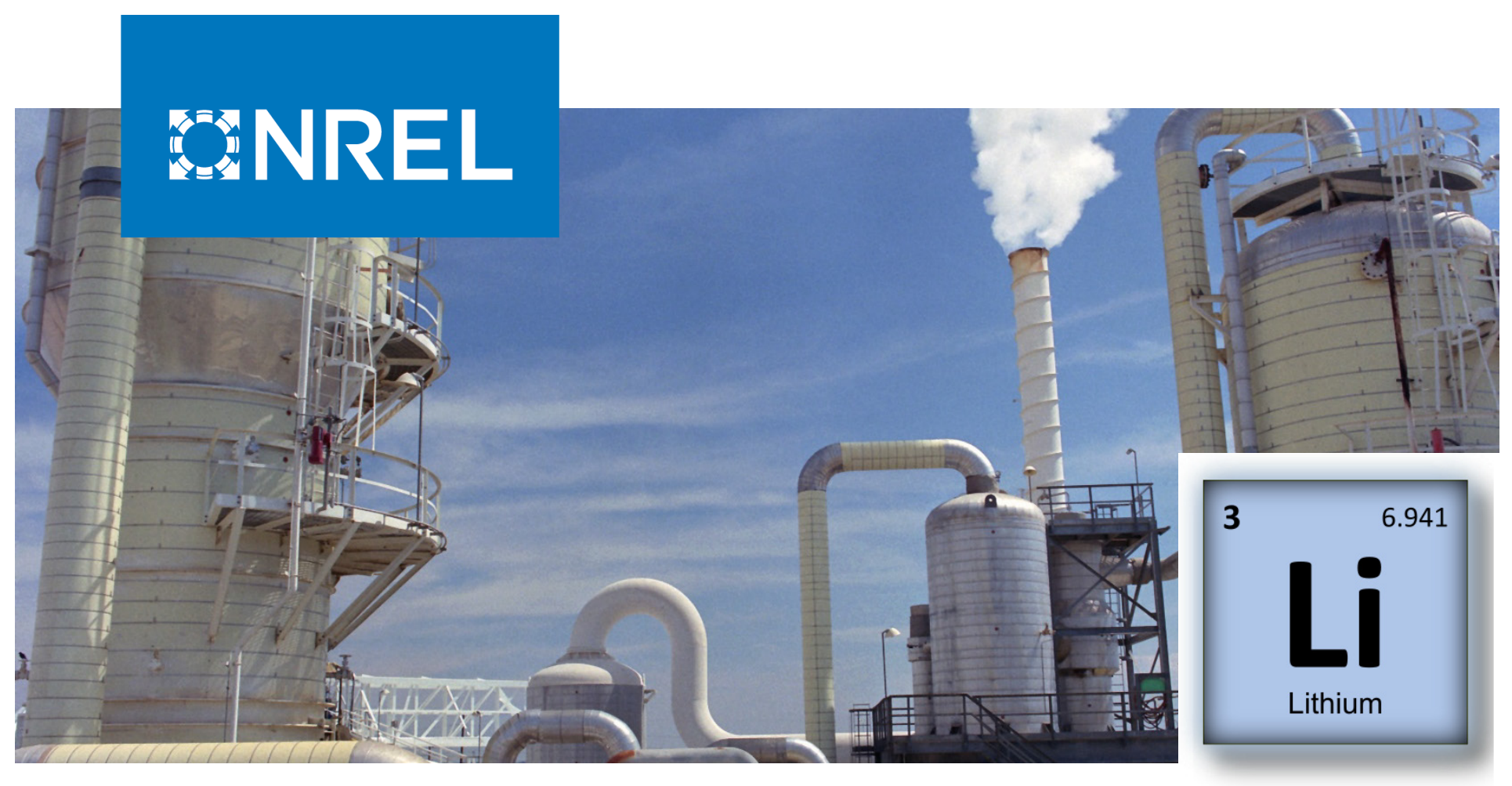

\title{
Techno-Economic Analysis of Lithium Extraction from Geothermal Brines
}

Ian Warren

National Renewable Energy Laboratory

NREL is a national laboratory of the U.S. Department of Energy

Office of Energy Efficiency \& Renewable Energy

Operated by the Alliance for Sustainable Energy, LLC

This report is available at no cost from the National Renewable Energy Laboratory (NREL) at www.nrel.gov/publications.
Technical Report

NREL/TP-5700-79178

May 2021 


\title{
GNREL
}

\section{Techno-Economic Analysis of Lithium Extraction from Geothermal Brines}

\author{
lan Warren
}

National Renewable Energy Laboratory

\section{Suggested Citation}

Warren, Ian. 2021. Techno-Economic Analysis of Lithium Extraction from Geothermal

Brines. Golden, CO: National Renewable Energy Laboratory. NREL/TP-5700-79178.

https://www.nrel.gov/docs/fy21osti/799178.pdf.

NREL is a national laboratory of the U.S. Department of Energy Office of Energy Efficiency \& Renewable Energy Operated by the Alliance for Sustainable Energy, LLC

This report is available at no cost from the National Renewable Energy Laboratory (NREL) at www.nrel.gov/publications.

Contract No. DE-AC36-08GO28308
Technical Report

NREL/TP-5700-79178

May 2021

National Renewable Energy Laboratory 15013 Denver West Parkway Golden, CO 80401

303-275-3000 • www.nrel.gov 


\section{NOTICE}

This work was authored by the National Renewable Energy Laboratory, operated by Alliance for Sustainable Energy, LLC, for the U.S. Department of Energy (DOE) under Contract No. DE-AC36-08GO28308. Funding provided by the U.S. Department of Energy Office of Energy Efficiency and Renewable Energy Geothermal Technologies Office. The views expressed herein do not necessarily represent the views of the DOE or the U.S. Government.

This report is available at no cost from the National Renewable Energy Laboratory (NREL) at www.nrel.gov/publications.

U.S. Department of Energy (DOE) reports produced after 1991 and a growing number of pre-1991 documents are available free via www.OSTI.gov.

Cover Photo by Warren Gretz: NREL 05559.

NREL prints on paper that contains recycled content. 


\section{Acknowledgments}

This project was funded by the U.S. Department of Energy's Geothermal Technologies Office. Maggie Mann and Eric Karp of the National Renewable Energy Laboratory (NREL) were helpful throughout the project, providing chemical engineering and techno-economic analysis expertise, respectively, and providing insightful reviews of draft reports. Alex Grant of Jade Cove Partners provided valuable insight into lithium supply chains and extraction technologies. His technical and business experience were particularly helpful with informing the technoeconomic analysis, as was his insightful review of draft reports. Jason Czapla of Controlled Thermal Resources reviewed draft reports and provided insight from an industry perspective. Thank you to Craig Turchi of NREL for his content review, and Deanna Cook for communications review. 


$\begin{array}{ll}\text { Acronyms } \\ \text { CTR } & \text { Controlled Thermal Resources } \\ \text { DLE } & \text { direct lithium extraction } \\ \text { DOE } & \text { U.S. Department of Energy } \\ \text { iLiaD } & \text { Integrated Lithium Adsorption Desorption } \\ \text { KGRA } & \text { Known Geothermal Resource Area } \\ \text { LCE } & \text { lithium carbonate equivalent } \\ \text { LDH } & \text { lithium-aluminum double hydroxide chloride } \\ \text { LHM } & \text { lithium hydroxide monohydrate } \\ \text { NREL } & \text { National Renewable Energy Laboratory } \\ \text { OPEX } & \text { operating expenses } \\ \text { PEA } & \text { Preliminary Economic Assessment } \\ \text { PFS } & \text { Pre-Feasibility Study } \\ \text { USGS } & \text { U.S. Geological Survey }\end{array}$

iv 


\section{Executive Summary}

The United States has a large, domestic source of lithium in geothermal fluids, especially at the Salton Sea region of southern California, where estimates of lithium pass-through at geothermal plants exceed 24,000 metric tons per year, based on 2019 geothermal plant operations. Lithium extraction from geothermal brines offers the potential to provide the United States with a secure, domestic supply of lithium to meet the increasing demands of electric vehicles, grid energy storage, portable electronics, and other end-use applications. Additionally, the use of direct extraction technologies allows for a more sustainable lithium supply relative to current evaporative brine and hardrock mining operations in terms of land use, water use, time to market with lithium products, and carbon intensity of operations. This report is part of an effort to assess geothermal brines as a source of commercial lithium supply for the United States. In this study, the National Renewable Energy Laboratory (NREL) reviews and summarizes public technoeconomic analyses of lithium extraction technologies. The work was coordinated with the Critical Minerals Institute at the Colorado School of Mines who focused on supply chain analysis of lithium.

Mineral extraction from geothermal brines in the Salton Sea and elsewhere has a decades-long history, but there have been few pilot-scale field tests focused on extraction of lithium from geothermal brines. There are also limited publicly available cost and performance data to fully evaluate the techno-economics of lithium extraction from geothermal brine. There are, however, demonstrations in progress that will more fully inform future analyses. For this report, technical and economic data are reviewed from projects focused on lithium extraction from geothermal and other brine types to assess the technologies being deployed and estimated costs to produce end products lithium carbonate $\left(\mathrm{Li}_{2} \mathrm{CO}_{3}\right)$ and lithium hydroxide monohydrate $\left(\mathrm{LiOH} \cdot \mathrm{H}_{2} \mathrm{O}\right)$. A review of these projects indicates expected production costs (i.e., operating expenses or OPEX) near $\$ 4,000 /$ metric ton of lithium carbonate equivalent (LCE) and reported internal rates of return suggest this production cost target is economically feasible with estimated prices of $\geq \$ 11,000 / \mathrm{mt}$ LCE. For comparison, market prices since mid-2018 have ranged from approximately $\$ 20,000 / \mathrm{mt}$ to $\$ 7,500 / \mathrm{mt} \mathrm{LCE}$.

Many techniques and process strategies have been proposed to extract lithium directly from geothermal and other brines, and these can be generally categorized into adsorption, ion exchange, and solvent extraction techniques. Of these technologies, the ones currently advancing to pilot- and near-commercial-scale demonstrations involve adsorption and ion exchange techniques.

Recent and ongoing lab studies on direct lithium extraction (DLE) from brines have focused largely on sorbent and solvent performance, with goals to increase lithium selectivity relative to competing ions, increase operating cycles between regeneration and replacement, and lower costs of sorbent and solvent manufacturing. DLE technologies also present the opportunity to increase sustainability and reduce overall impacts when compared to traditional evaporative pond and hardrock mining methods for producing lithium. Improved performance of sorbent and solvents will be primary drivers of future cost reductions and improved economics for lithium extraction from geothermal brines. There is a diverse array of research focused on lithium extraction from brines, and continued lab-scale work may improve current techniques or identify new techniques that contribute toward commercialization. Geothermal operators at the Salton 
Sea are actively engaged in steps to commercialize lithium extraction, and these projects offer the potential to demonstrate whether commercialization is feasible over the next few years. As a valuable by-product, lithium production has the potential to improve the economics and increase development of geothermal power generation at the Salton Sea Known Geothermal Resource Area (KGRA).

Additional considerations beyond the specific cost and performance of lithium extraction processes relate to impacts of the tail fluid on the geothermal reservoir. After lithium removal, this injectate fluid might be cooler than the normal power plant rejection temperature. Resaturation of the brine with lithium could be affected by injectate access to lithium-bearing rocks in the reservoir and by injectate residence time. Reservoir modeling combined with details of lithium distribution in the reservoir could clarify the importance of these potential impacts to reservoir brine chemistry and resource heat content. 


\section{Table of Contents}

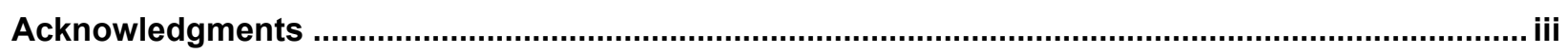

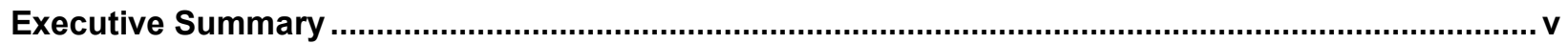

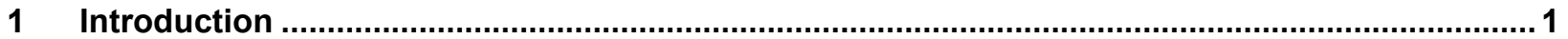

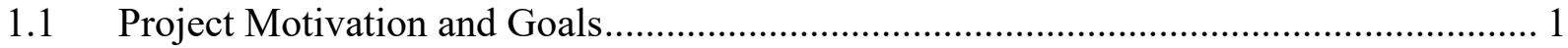

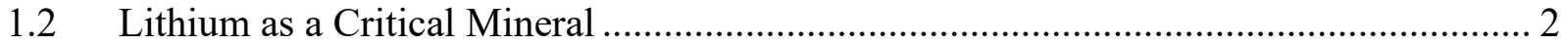

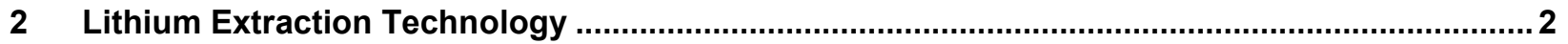

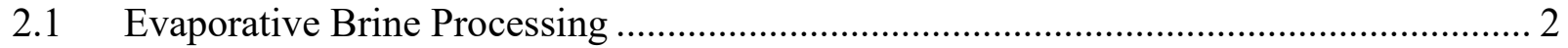

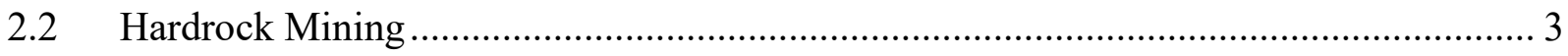

2.3 Other Methods of Lithium Extraction ................................................................... 3

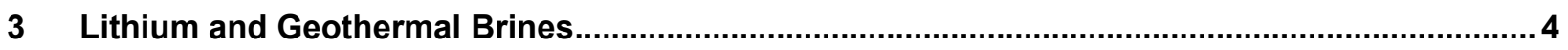

3.1 Lithium Occurrence in Geothermal Brines ............................................................. 4

3.2 Overview of Minerals Extraction from Geothermal Brines...................................... 5

3.3 DOE Support of Lithium Extraction from Geothermal Brines ................................. 8

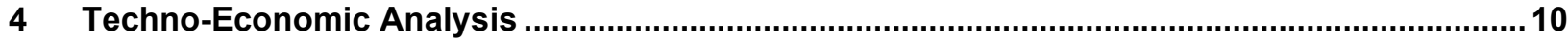

4.1 Proposed Direct Lithium Extraction Projects................................................... 10

4.2 DLE from Salton Sea Geothermal Brines ........................................................ 14

4.3 Planned and Ongoing Demonstrations ................................................................... 18

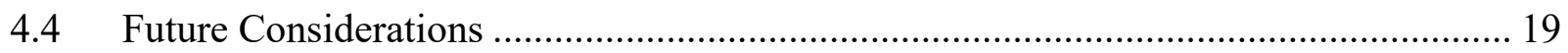

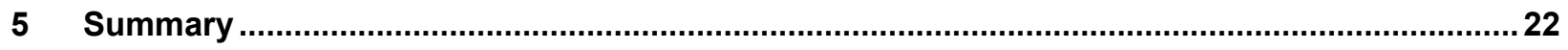

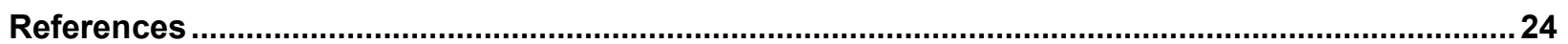

Appendix A. Lithium Extraction Process Details ......................................................................29 


\section{List of Figures}

Figure 1. Schematic representation of direct lithium extraction processes (image courtesy of Jade

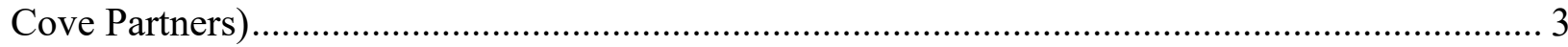

Figure 2. Lithium concentrations in geothermal fluids of the western United States.................. 5

Figure 3. Lithium extraction process of Schultze and Bauer (1984) ...................................... 8

Figure 4. Simple schematic of power generation process at Salton Sea................................. 15

Figure 5. Detailed process steps for production of lithium with ILiAD technology .................. 17

Figure 6. Details of the continuous countercurrent adsorption and desorption process .............. 17

Figure 7. Lithium selectivity based on pilot testing of ILiAD technology ............................... 18

Figure A-1. Schematic representation of the lithium extraction process proposed by Renew and

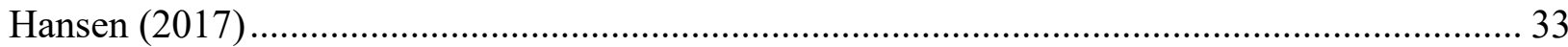

Figure A-2. Vulcan Energy Resources' proposed hybrid geothermal and lithium extraction

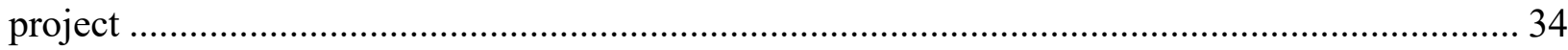

Figure A-3. Schematic representation of Standard Lithium's lithium extraction process........... 35

Figure A-4. Schematic representation and process flow chart of E3 Metal Corp.'s lithium

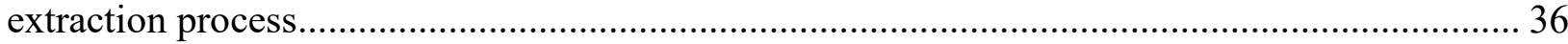

Figure A-5. Schematic diagram of Anson's proposed bromine and lithium extraction process .. 37

Figure A-6. Lithium recovery flowsheet for Pure Energy Minerals' Clayton Valley project...... 38

Figure A-7. Schematic representation of Lake Resources proposed ion-exchange process to

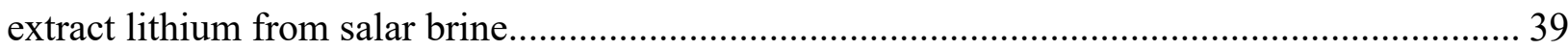

\section{List of Tables}

Table 1. Composition of Select Production Fluids from the Salton Sea KGRA ......................... 6

Table 2. Lithium Species Conversion Factors ................................................................ 10

Table 3. Summary of DLE Project Economics.................................................................. 12

Table 4. Standard Lithium's Estimated Annual OPEX in U.S. Dollars for the Smackover

Evaporite Brine DLE Project .................................................................................... 13

Table 5. E3 Metal Corp's Estimated OPEX in Canadian Dollars for the Clearwater Oilfield Brine

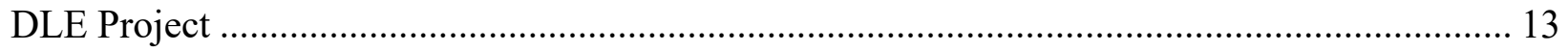

Table 6. Anson Resources' Estimated Annual OPEX for the Paradox Basin DLE Project ......... 14

Table 7. Lake Resources' Estimated Annual and Specific OPEX for the Kachi DLE Project .... 14

Table 8. Techniques for Extraction of Lithium from Brines That Show the Breadth of Recent

Research Efforts .............................................................................................. 20

Table A-1. Chemical Analyses of Fluids from Lithium Extraction Pilot Tests at Elmore and Featherstone Geothermal Power Plants, Salton Sea KGRA ............................................... 31 


\section{Introduction}

This report is part of an effort to assess geothermal brines as a source of commercial lithium supply for the United States. To do this, the National Renewable Energy Laboratory (NREL) reviewed published techno-economic analysis of lithium extraction technologies and coordinated with the Critical Minerals Institute at the Colorado School of Mines, which focused on supply chain analysis of lithium. Data sources included studies sponsored by the U.S. Department of Energy (DOE) Geothermal Technologies Office, which previously funded projects to support advancement of mineral recovery from geothermal brines, exploring the added value of strategic minerals recovery in geothermal operations. Now, there is renewed focus on lithium as a critical material with growing demand, particularly demand for lithium-ion batteries. Geothermal brines are potential lithium sources; lithium production as a by-product can potentially support geothermal operations with increased revenues while helping secure U.S. domestic lithium supply.

\subsection{Project Motivation and Goals}

Lithium extraction from geothermal brines offers the potential to provide the United States with a secure, domestic supply of lithium to meet the increasing demands of electric vehicles, grid energy storage, portable electronics, and other end-use applications. The latest U.S. Geological Survey's (USGS) Mineral Commodities Summary (Jaskula 2020) estimates that 65\% of the lithium end use globally is for lithium-ion batteries, and this market is expected to grow rapidly in coming years. From 2015-2019, net import reliance as a percentage of estimated consumption was typically $>50 \%$, with imports primarily coming from Argentina $(53 \%)$, Chile (40\%), and China (3\%). With the addition of Australia, these countries are responsible for the majority of lithium production globally and produce lithium from brine and hardrock mining operations. In 2018, estimated lithium extraction and processing from evaporation ponds and hardrock leaching made up approximately $46 \%$ and $54 \%$, respectively, of the current economically profitable lithium production methods (Facada 2019).

Lithium extraction from geothermal brine could change the U.S. lithium supply significantly due to the high lithium concentrations at some geothermal fields, particularly those at the Salton Sea Known Geothermal Resource Area (KGRA). Reported 2019 brine flow from the Salton Sea geothermal wellfields is 121,308,148 metric tons (mt) (CalGEM 2019), and a conservative average lithium concentration in geothermal brine is $200 \mathrm{mg} / \mathrm{L}$ (McKibben and Hardie 1997). This represents an estimated annual lithium throughput of approximately $24,000 \mathrm{mt}$ that can be converted to nearly $127,000 \mathrm{mt}$ of lithium carbonate. This is significant-U.S. lithium consumption from 2015 through 2019 is estimated to be 2,000-3,000 mt per year, which can be converted to nearly 16,000 mt of lithium carbonate equivalent (LCE) (Jaskula 2020). The Salton Sea KGRA currently has an inferred lithium resource of 15 million mt (Chao 2020). A fully developed Salton Sea KGRA would be capable of producing more than $600,000 \mathrm{mt}$ of LCE per year (Ventura et al. 2020).

Additional motivation comes from the sustainability of extracting lithium from geothermal brines relative to evaporative brine and hardrock mining operations in terms of land use, water use, time to market with lithium products, and carbon intensity of operations. Extraction of lithium from geothermal brines can take advantage of on-site renewable power, heat exchange, 
fluid handling and treatment equipment, and water (condensed steam), while the barren brine at the end of the lithium extraction process is returned to the reservoir via injection wells to complete the power production cycle.

\subsection{Lithium as a Critical Mineral}

In 2018, lithium was identified as a critical mineral by the U.S. Department of the Interior pursuant to Presidential Executive Order No. 13817, "A Federal Strategy to Ensure Secure and Reliable Supplies of Critical Minerals" (Fortier et al. 2018). Response to the Executive Order was coordinated by the Secretary of the Interior, in coordination with the Secretary of Defense, and in consultation with the heads of other relevant executive departments and agencies. Critical minerals are formally defined as a mineral:

(1) identified to be a nonfuel mineral or mineral material essential to the economic and national security of the United States, (2) from a supply chain that is vulnerable to disruption, and (3) that serves an essential function in the manufacturing of a product, the absence of which would have substantial consequences for the U.S. economy or national security. (Fortier et al. 2018)

Though used in other applications, lithium is notable as a component of rechargeable batteries. This demand has been dominated by portable electronic devices but is expected to grow significantly in the future with wider deployment of electric vehicles and grid energy storage (Fortier et al. 2018).

\section{Lithium Extraction Technology}

A range of physical and chemical techniques can be used to extract lithium from brines and ores. The current marketplace is dominated by established companies that produce lithium from brines, especially in the dry, high altitude salars of the "Lithium Triangle" (Argentina, Chile, and Bolivia) using evaporative and chemical reagent separation methods and from hardrock mines, especially in Australia, using energy-intensive separation and metallurgical processes. Established producers, especially those able to adjust operations to follow market trends, have a large influence on conditions in the marketplace. Since mid-2018, lithium carbonate spot market prices have ranged from approximately $\$ 20,000 / \mathrm{mt}$ to $\$ 7,500 / \mathrm{mt}$ and lithium hydroxide monohydrate from $\$ 21,000 / \mathrm{mt}$ to $\$ 10,000 / \mathrm{mt}$ (Fastmarkets, 2021) with lowest prices coming during the COVID-19-related, global economic downturn and reduction in demand.

\subsection{Evaporative Brine Processing}

The standard practice for lithium extraction from brine involves pumping the lithium-rich brine to a series of ponds at surface that can occupy thousands of acres. In the ponds, lithium and other salts are concentrated via passive solar evaporation for a year or longer. After the water has evaporated to sufficiently concentrate lithium to approximately $6,000 \mathrm{mg} / \mathrm{kg}$, non-lithium constituents not removed previously with successive evaporative concentrations steps are separated by precipitation with addition of chemical reagents, primarily slaked lime $\left(\mathrm{Ca}(\mathrm{OH})_{2}\right)$. The remaining lithium-enriched solution is transferred to a processing plant where remaining unwanted constituents are removed from the solution by additional non-evaporative techniques that are typically proprietary but can include addition of reagents, filtration, solvent extraction, and ion exchange. The purified, lithium-concentrated brine is chemically treated with soda ash 
$\left(\mathrm{Na}_{2} \mathrm{CO}_{3}\right)$ to produce lithium carbonate $\left(\mathrm{Li}_{2} \mathrm{CO}_{3}\right)$ or further processed to produce lithium hydroxide $\left(\mathrm{LiOH} \cdot \mathrm{H}_{2} \mathrm{O}\right)$. Though operators work to refine their processes, evaporative brine processing typically only recovers $\sim 50 \%$ of the original lithium content of the native brine. According to S\&P Global Market Intelligence (2019), production costs across 9 brine operations average $\$ 5,580 / \mathrm{mt} \mathrm{LCE}$.

\subsection{Hardrock Mining}

The most valuable hardrock mines are dominated by granite pegmatites that contain the lithiumbearing mineral spodumene with a theoretical $\mathrm{Li}_{2} \mathrm{O}$ content of $8 \mathrm{wt} . \%$. A typical run of mine ore contains $1 \%-2 \% \mathrm{Li}_{2} \mathrm{O}(\sim 20 \%$ spodumene), and after processing, a typical lithium concentrate ready for $\mathrm{Li}_{2} \mathrm{CO}_{3}$ production contains $6 \%-7 \% \mathrm{Li}_{2} \mathrm{O}(\sim 80 \%$ spodumene). Ore processing involves the crushing of mined ore, Li-mineral concentration via floatation, roasting at $\sim 1,050^{\circ} \mathrm{C}$, and treatment with sulfuric acid and a second roasting at $\sim 200^{\circ} \mathrm{C}$ to produce a lithium concentrate. The lithium concentrate is processed into $\mathrm{Li}_{2} \mathrm{CO}_{3}$ or $\mathrm{LiOH} \cdot \mathrm{H}_{2} \mathrm{O}$ via multi-step processes involving leaching, liquid-solid separation, and impurity removal via precipitation and ion exchange. According to S\&P Global Market Intelligence (2019), production costs across 11 hardrock mining operations averaged $\$ 2,540 / \mathrm{mt} \mathrm{LCE}$. However, this is the cost to produce mining concentrate that must be converted to end-use products like lithium carbonate and lithium hydroxide. Conversion to these battery-grade forms can cost $\$ 2,000-2,500 / \mathrm{mt}$ of mined concentrate depending on the lithium concentration and bulk chemistry.

\subsection{Other Methods of Lithium Extraction}

A variety of strategies to extract lithium from brines have been investigated, including precipitation, adsorption, solvent, ionic liquid, membrane, electrochemical, and chromatographic techniques, see Figure 1 (Flexer et al. 2018; Ling et al. 2018; Liu et al. 2019; Schmidt et al. 2019; Zhao et al. 2019; Stringfellow and Dobson 2021).

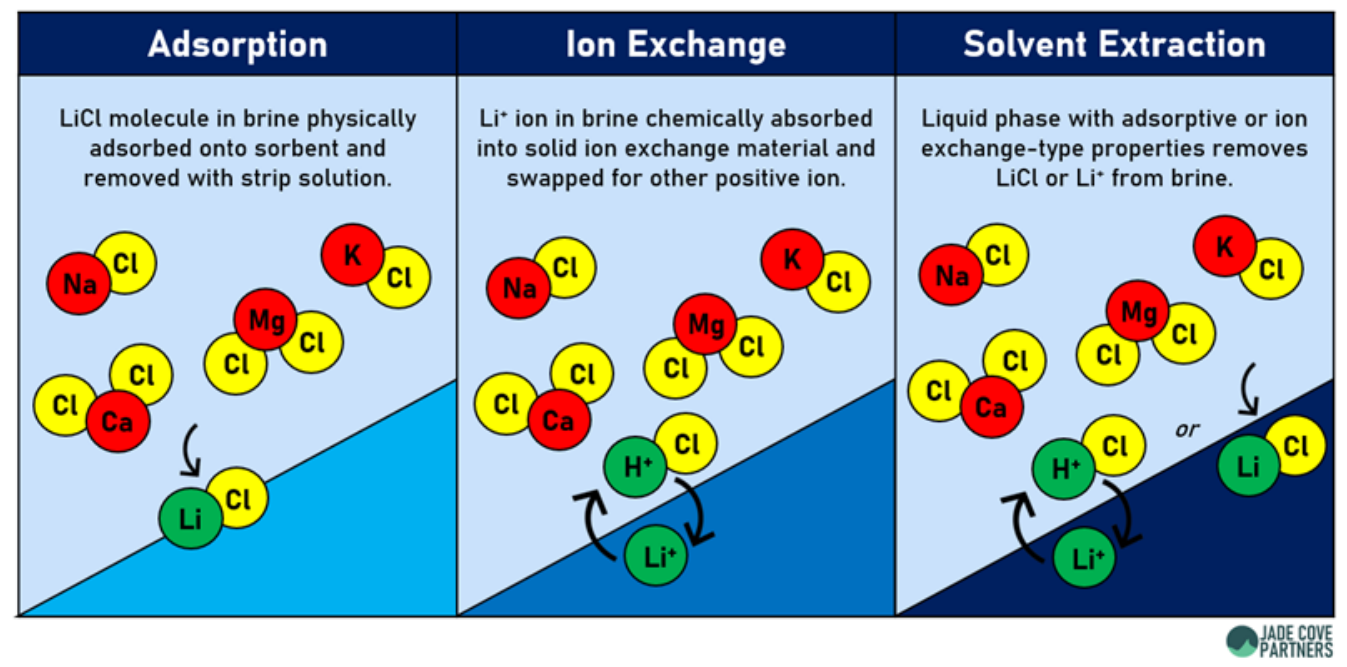

Figure 1. Schematic representation of direct lithium extraction processes (image courtesy of Jade Cove Partners) 
Lithium extraction processes may use a combination of techniques to produce final, high-purity lithium products (Xu et al. 2021). Of the novel processes proposed for lithium extraction from brines, those currently being advanced toward pilot and commercial scale are referred to as direct lithium extraction (DLE). DLE technologies can be added to existing geothermal power plants or built into the design of future plants and have distinct advantages over evaporative ponds and hardrock mining with respect to sustainability related to land use, water use, time to market with lithium products, and carbon intensity of operations.

DLE technologies can be broadly grouped into three main categories: adsorption, ion exchange, and solvent extraction. The adsorption process physically adsorbs $\mathrm{LiCl}$ molecules onto the surface of a sorbent from a lithium-loaded solution with water as a potential stripping solution. Ion exchange takes lithium ions from the solution by trading lithium ions for protons or other cations within the sorbent's structure. An acid solution is typically required for stripping and recovering the lithium. Solvent extraction exchanges $\mathrm{LiCl}$ molecules or lithium ions between brine and an organic liquid phase containing an extractant that complexes with lithium or lithium compounds in the brine. To successfully be deployed, DLE techniques (alone or in combination with additional process steps) must be able to extract lithium from complex brines with high concentrations of ions such as sodium, potassium, calcium, magnesium, borates, sulfates, and for geothermal brines, silica, and potentially other species (e.g., iron and manganese that have high concentrations in Salton Sea brines).

\section{Lithium and Geothermal Brines}

\subsection{Lithium Occurrence in Geothermal Brines}

The potential for the recovery of valuable minerals from geothermal brines has been recognized for decades, and efforts in the United States have mainly focused on the mineral-rich brines of the Salton Sea KGRA, which developed through a complex and unique geologic history and location along an active tectonic boundary. Recent studies have looked at the broader U.S. occurrence of valuable minerals in geothermal brines. Neupane and Wendt (2017) examined more than 2,250 chemical analyses of geothermal fluids primarily in the western United States that were compiled by the USGS (Figure 2). Notably, less than $1 \%$ of samples have lithium concentrations $>20 \mathrm{mg} / \mathrm{kg}$, and the highest concentrations are from the Salton Sea, with values up to $400 \mathrm{mg} / \mathrm{kg}$. Similarly high lithium concentrations are also reported for continental brines in Arkansas (Figure 2; Appendix A.5). Simmons et al. (2018) investigated strategic and critical element occurrence in geothermal and oilfield brines from Nevada and Utah with new sampling and analyses, and only a single sample from Roosevelt Hot Springs, Utah $(25 \mathrm{mg} / \mathrm{kg})$ was found to have lithium concentration $>10 \mathrm{mg} / \mathrm{kg}$. 


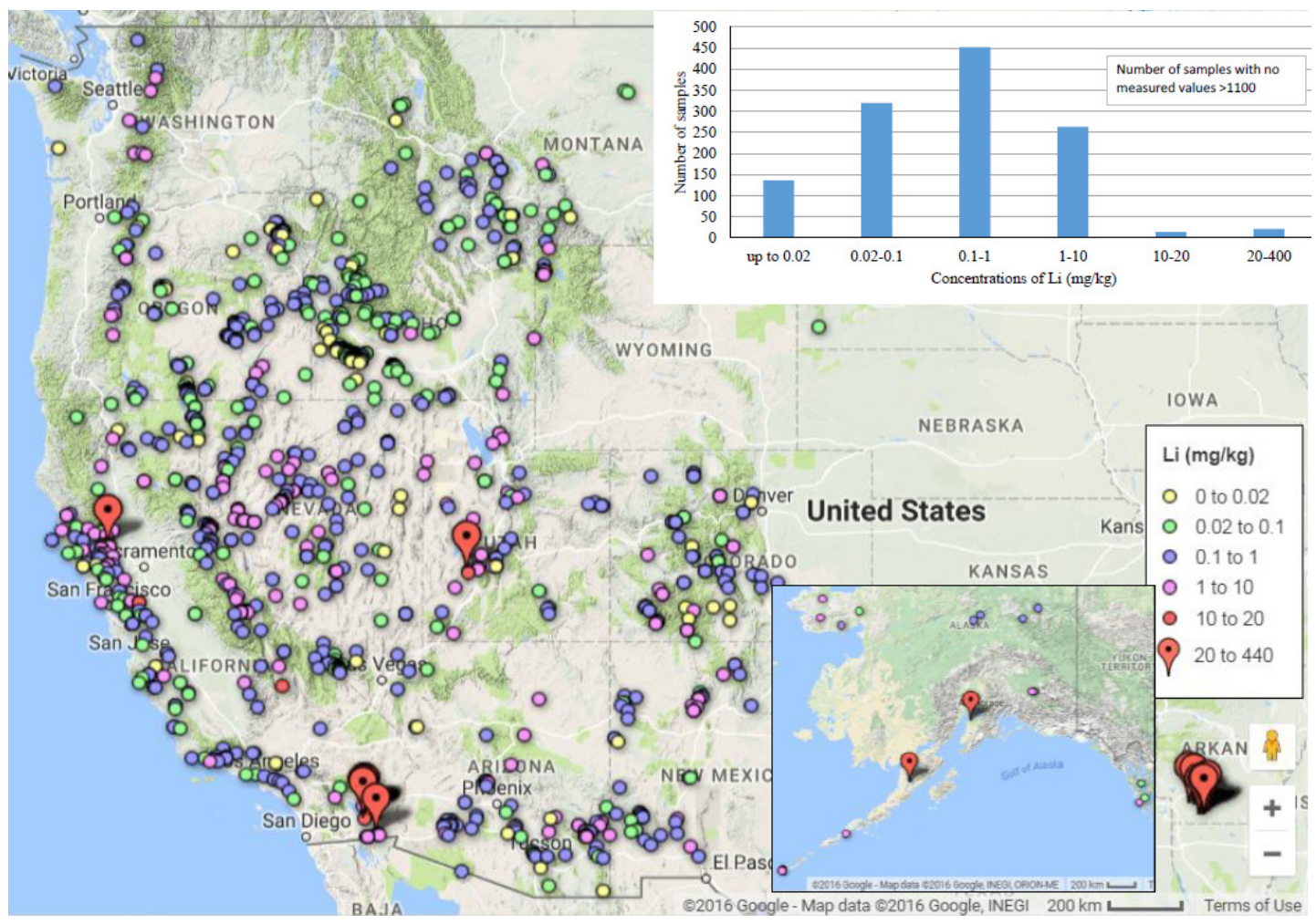

Figure 2. Lithium concentrations in geothermal fluids of the western United States

Figure from Neupane and Wendt (2017)

Outside of the United States, there is active engagement from government, industry, and academia focused on lithium extraction from geothermal brines in the Upper Rhine Valley of southwest Germany and in Alsace, France. Upper Rhine Valley geothermal fluids have measured temperatures up to $200^{\circ} \mathrm{C}$ and lithium concentrations up to $210 \mathrm{mg} / \mathrm{L}$ (Sanjuan et al. 2016). In Alsace, France, geothermal fluids have measured temperatures up to $205^{\circ} \mathrm{C}$ and lithium concentrations up to $162 \mathrm{mg} / \mathrm{L}$ (Sanjuan et al. 2020). Extraction from less lithium-rich brines has also been studied at Wairakei, New Zealand, where lithium concentrations are only $\sim 13 \mathrm{mg} / \mathrm{L}$ (Mroczek et al. 2015).

\subsection{Overview of Minerals Extraction from Geothermal Brines}

Some of the first work on lithium extraction from geothermal brines began decades ago at the Wairakei geothermal field in New Zealand (Kennedy 1961). The proposed process was primary concentration via electrolysis and secondary concentration via evaporation; however, recovery of lithium, in addition to sodium and potassium, was not deemed economic at the time.

The most salt-laden geothermal brines in the United States (20\%-30\% total dissolved solids) are located at the Salton Sea KGRA (Table 1). That is where much of the U.S. effort to study mineral recovery from geothermal brines has been focused. Investigating both scaling management and minerals extraction at the Salton Sea, one of the earliest studies (Werner 1970) suggested sorption of metal ammines (metal- $\mathrm{NH}_{3}$ complexes, typically with $\mathrm{Cl}$ counter ions) on activated charcoal/coke followed by evaporation in multiple ponds to concentrate species sequentially to precipitate chloride salts of sodium, potassium, calcium, magnesium, lithium, and others. 
Table 1. Composition of Select Production Fluids from the Salton Sea KGRA

\begin{tabular}{|c|c|c|c|c|c|c|c|c|c|c|c|c|c|c|}
\hline Well Name & SSSDP State 2-14 & SSSDP State 2-142 & SSSDP State 2-143 & Well 11b & Well 10 & Unnamed Well & Magmamax 1 & Magmamax 14 & Hudson Ranch Well & IIID-1 & IIID-2 & Sinclair \#4 & Fee 5 & Fee 6 \\
\hline Date sampled & $12 / 1 / 1985$ & 3/1/1986 & $6 / 1 / 1988$ & & & & 7/1/1979 & $8 / 1 / 1976$ & & $4 / 21 / 1966$ & & & $8 / 15 / 1984$ & $3 / 1 / 1985$ \\
\hline Depth (m) & $1,850-1,890$ & $2,500-3,220$ & $1,830-2,200$ & $660-1,070$ & $700-1,070$ & & 855 & 855 & & 1,595 & 1,776 & 1,615 & $\sim 3,500$ & $\sim 3,500$ \\
\hline $\mathrm{T}^{\circ} \mathrm{C}$ & 305 & 330 & 320 & 300 & 295 & & & 215 & & 340 & 332 & 260 & $\sim 300$ & $\sim 300$ \\
\hline $\mathrm{pH}$ & 5.4 & 5.1 & 5.3 & 5.2 & 5.3 & 5.3 & & 5.2 & & 5.2 & & 5.3 & & \\
\hline Units & $\mathrm{ppm}$ & $\mathrm{ppm}$ & $\mathrm{ppm}$ & $\mathrm{ppm}$ & $\mathrm{ppm}$ & $\mathrm{ppm}$ & $\mathrm{mg} / \mathrm{L}$ & $\mathrm{ppm}$ & $\mathrm{ppm}$ & $\mathrm{ppm}$ & $\mathrm{ppm}$ & $\mathrm{ppm}$ & $\mathrm{ppm}$ & $\mathrm{ppm}$ \\
\hline $\mathrm{Na}$ & 53,000 & 54,800 & 53,700 & 46,200 & 41,400 & 52,700 & 43,000 & 42,000 & 56,275 & 50,400 & 53,000 & 58,443 & 43,500 & 48,100 \\
\hline $\mathrm{Ca}$ & 27,400 & 28,500 & 26,300 & 22,800 & 20,900 & 26,500 & 22,300 & 20,000 & 29,778 & 28,000 & 27,800 & 26,992 & 27,700 & 28,700 \\
\hline $\mathrm{k}$ & 16,700 & 17,700 & 17,100 & 12,500 & 11,800 & 16,500 & 7,550 & 8,600 & 18,006 & 17,500 & 16,500 & 14,918 & 16,200 & 14,500 \\
\hline $\mathrm{Fe}$ & 1,560 & 1,710 & 1,620 & 582 & 969 & 1,550 & 220 & 256 & 1,411 & 2,090 & 2,000 & 1,148 & 1,890 & 1,920 \\
\hline $\mathrm{Mn}$ & 1,450 & 1,500 & 1,470 & 801 & 855 & 1,390 & 420 & 690 & 1,700 & 1,560 & 1,370 & 1,025 & 1,430 & 1,650 \\
\hline $\mathrm{SiO} 2$ & $>461$ & $>588$ & $>840$ & $>336$ & $>404$ & 475 & & 432 & 437 & 400 & 400 & 90 & 354 & 243 \\
\hline Al & 2 & & & & & 3 & & 1 & & 4.2 & & & & 1.8 \\
\hline $\mathrm{Rb}$ & 170 & & & & & & & 64 & & 137 & 70 & & & \\
\hline $\mathrm{Zn}$ & 518 & 507 & 510 & 321 & 323 & 506 & 105 & 361 & 487 & 790 & 500 & & 551 & 558 \\
\hline $\mathrm{Ag}$ & & & & & & 2 & & & & 0.8 & 2 & & & \\
\hline As & & & & & & 5 & & & 12 & 12 & & 10 & & \\
\hline $\mathrm{Sr}$ & 411 & 421 & 410 & 376 & 345 & & 460 & 388 & 316 & 609 & 440 & 434 & 426 & 489 \\
\hline B & 257 & 271 & 380 & 204 & 197 & 268 & & & 563 & 390 & 390 & 332 & 319 & 274 \\
\hline $\mathrm{Ba}$ & 203 & $<353$ & 218 & 183 & 156 & 194 & 130 & 118 & 167 & 235 & 250 & & 270 & 300 \\
\hline $\mathrm{Li}$ & 194 & 209 & 215 & 157 & 152 & 230 & 170 & 141 & 228 & 215 & 210 & 287 & 228 & 216 \\
\hline $\mathrm{Mg}$ & 33 & 49 & 43 & 19 & 33 & 36 & 150 & 80 & 43 & 54 & 10 & 736 & 96 & 81 \\
\hline $\mathrm{Pb}$ & 100 & 102 & 107 & 69 & 67 & 91 & 50 & 78 & 108 & 84 & 80 & & 63 & 111 \\
\hline $\mathrm{Cu}$ & 5.9 & 6.8 & 5.8 & NA & 2 & & 2.5 & 1 & 0.9 & 8 & 3 & & 3.9 & 2.3 \\
\hline $\mathrm{Cd}$ & 2.2 & 2.3 & 2.2 & 1 & 1.4 & & & & & & & & 2.2 & 2.2 \\
\hline Cs & 20 & NA & 23 & NA & NA & & & & & 16 & 20 & & & \\
\hline $\mathrm{NH} 4$ & 333 & 330 & 356 & 339 & 341 & & 335 & 45 & & 409 & & & & \\
\hline $\mathrm{Cl}$ & 151,000 & 157,500 & 152,000 & 128,000 & 116,000 & 174,900 & 115,200 & 121,000 & 165,442 & 155,000 & 155,000 & 154,590 & 139,000 & 127,000 \\
\hline $\mathrm{F}$ & 15 & & & & & & & & 7.2 & 15 & & 14 & & \\
\hline $\mathrm{Br}$ & 99 & 111 & 111 & 95 & 78 & & & & & 120 & & 25 & 94 & 90 \\
\hline 1 & 20 & & & & & & & & & 18 & & 13 & & \\
\hline $\mathrm{SO} 4$ & 65 & 53 & 123 & 100 & 53 & & & & & 5.4 & & 19 & 35 & 74 \\
\hline TDS (\%) & 25.6 & 26.5 & 25.6 & 21.4 & 20 & 29.5 & 21.5 & 20.8 & 27.9 & 25.8 & 25.9 & 26.7 & 23.8 & 23 \\
\hline References & $\begin{array}{l}\text { Williams and } \\
\text { McKibben 1989; } \\
\text { McKibben and } \\
\text { Hardie } 1997\end{array}$ & $\begin{array}{l}\text { Williams and } \\
\text { McKibben 1989; } \\
\text { McKibben and } \\
\text { Hardie } 1997\end{array}$ & $\begin{array}{l}\text { Williams and } \\
\text { McKibben 1989; } \\
\text { McKibben and } \\
\text { Hardie } 1997\end{array}$ & $\begin{array}{l}\text { Williams } \\
\text { and } \\
\text { McKibben } \\
\text { 1989; } \\
\text { McKibben } \\
\text { and Hardie } \\
1997\end{array}$ & $\begin{array}{l}\text { Williams and } \\
\text { McKibben } \\
\text { 1989; } \\
\text { McKibben } \\
\text { and Hardie } \\
1997\end{array}$ & $\begin{array}{l}\text { Duyvesteyn } \\
1992\end{array}$ & $\begin{array}{l}\text { Featherstone } \\
\text { and Powell } 1981\end{array}$ & Maimoni 1982 & $\begin{array}{l}\text { CA regional water } \\
\text { quality control } \\
\text { board Order R7- } \\
2013-0059\end{array}$ & $\begin{array}{l}\text { Skinner et } \\
\text { al. 1967; } \\
\text { Blake } \\
\text { 1974; } \\
\text { Palmer } \\
1975\end{array}$ & $\begin{array}{l}\text { Skinner et } \\
\text { al. 1967; } \\
\text { Palmer } \\
1975\end{array}$ & t Palmer 1975 & $\begin{array}{l}\text { Zukin et al. } \\
1987\end{array}$ & $\begin{array}{l}\text { Zukin et al. } \\
1987\end{array}$ \\
\hline Comments & $\begin{array}{l}\text { Flash corrected } \\
\text { brine analyses }\end{array}$ & $\begin{array}{l}\text { Flash corrected } \\
\text { brine analyses; } \\
\text { may be } \\
\text { contaminated by } \\
\text { drilling fluids }\end{array}$ & $\begin{array}{l}\text { Flash corrected } \\
\text { brine analyses; may } \\
\text { be contaminated } \\
\text { by drilling fluids }\end{array}$ & $\begin{array}{l}\text { Flash } \\
\text { corrected } \\
\text { brine } \\
\text { analyses }\end{array}$ & $\begin{array}{l}\text { Flash } \\
\text { corrected } \\
\text { brine } \\
\text { analyses }\end{array}$ & & & & $\begin{array}{l}\text { Average produced } \\
\text { brine composition } \\
\text { (production wells } \\
13-1,13-2, \text { \& 13-3) }\end{array}$ & $\begin{array}{l}\text { Corrected } \\
\text { for steam } \\
\text { loss }\end{array}$ & $\begin{array}{l}\text { Average } \\
\text { analysis, } \\
\text { corrected } \\
\text { for steam } \\
\text { loss }\end{array}$ & $\begin{array}{l}\text { Average } \\
\text { analysis, } \\
\text { corrected for } \\
\text { steam loss }\end{array}$ & $\begin{array}{l}\text { Flash } \\
\text { corrected } \\
\text { brine } \\
\text { analyses }\end{array}$ & $\begin{array}{l}\text { Flash } \\
\text { corrected } \\
\text { brine } \\
\text { analyses }\end{array}$ \\
\hline
\end{tabular}


The U.S. Bureau of Mines studied mineral contents of Salton Sea geothermal fluids and processes for extracting precious and base metals in the 1970s and 1980s (Christopher et al. 1975; Berthold and Baker 1976; Berthold and Stephens 1978; Maimoni 1982; Schultze and Bauer 1982; 1984), while Dow Chemical Company began development of ion exchange resins for lithium recovery from brines that culminated in development of refined ion-exchange pellets containing microcrystalline lithium-aluminum salts (Lee and Bauman 1978; 1980; Burba III 1985; Bauman and Burba III 1995; 2001).

Christopher et al. (1975) developed hydrometallurgical techniques for recovery of iron, manganese, zinc, lead, barium, lithium, and ammonia from Salton Sea geothermal brines. Iron and manganese hydrated oxide compounds, including zinc and lead compounds, were coprecipitated with manganese hydrated oxide. Ninety-nine percent of the metals were precipitated at $\mathrm{pH} 8.7$ under non-oxidized conditions with addition of lime, and the remaining metals were precipitated under oxidizing alkaline conditions with addition of lime.

Berthold and Baker (1976) described lithium recovery using ion-exchange and precipitation methods. Pre-treatment of post-flash Salton Sea brine removed silica, iron, manganese, zinc, and lead by raising $\mathrm{pH}$ to $7.5-8$ to precipitate metal hydroxides. The clarified fluid could be further concentrated using solar- and geothermal-heat-driven evaporation with the limit on concentration constrained by $\mathrm{CaCl}_{2}$ saturation. Their preferred method for lithium extraction was via precipitation of $\mathrm{LiOH}$ by addition of $\mathrm{AlCl}_{3}$ with $\mathrm{pH}$ control. Optimal lithium recovery $(>98 \%)$ was achieved with $\mathrm{Al} / \mathrm{Li}$ ratios of $3 / 1, \mathrm{pH} 7.5$, and temperature $75^{\circ}-85^{\circ} \mathrm{C}$. An important lesson for lithium extraction was noted by the authors - optimal lithium recovery parameters will vary based on the specific physical and chemical properties of target geothermal fluids.

Bench-scale experiments led to field demonstrations with post-flash fluid flow rates up to 10 gallons per minute (gpm; 37.85 liters per minute) and treatment with lime (27 lbs per 1,000 gallons brine; $12.25 \mathrm{~kg}$ per 3,785 liters brine) to remove silica and to precipitate iron, manganese, lead, and zinc (Schultze and Bauer 1982). The various process strategies that were tested encountered difficulties with silica removal and separation of precipitated metals. Schultze and Bauer (1984) described one of the earliest processes considered economic for recovery of lithium from geothermal brines at the Salton Sea, with recovery of $99 \%$ of lithium as $\mathrm{LiCl}$ (Figure 3). The process required addition of $\mathrm{AlCl}_{3}$ solution and raising $\mathrm{pH}$ to 7.5 with a lime slurry. $\mathrm{Li}-\mathrm{Al}$ precipitate was dissolved in $\mathrm{HCl}$ and sparged with gaseous $\mathrm{HCl}$ to remove $\mathrm{AlCl}_{3}$ and produce a solution with $\mathrm{LiCl}$ and $\mathrm{CaCl}_{2}$. Evaporation of the solution at $100^{\circ} \mathrm{C}$ left $97 \%$ of the lithium with $90 \%$ of $\mathrm{Ca}$ rejected via dissolution in tetrahydrofuran, which was subsequently evaporated. The final lithium product was purified by dissolving in water and treating with oxalic acid to recover $89 \%$ of the original lithium with a purity of $99.9 \%$. Though the authors concluded that $\mathrm{LiCl}$ could be extracted economically from geothermal brine at the Salton Sea, the estimated cost of $\$ 2.99$ per pound $\mathrm{LiCl}(\$ 6,590 / \mathrm{mt} \mathrm{LiCl}$; Schultze and Bauer 1984) equates to approximately $\$ 16,700 / \mathrm{mt} \mathrm{LiCl}$ in today's dollars. 


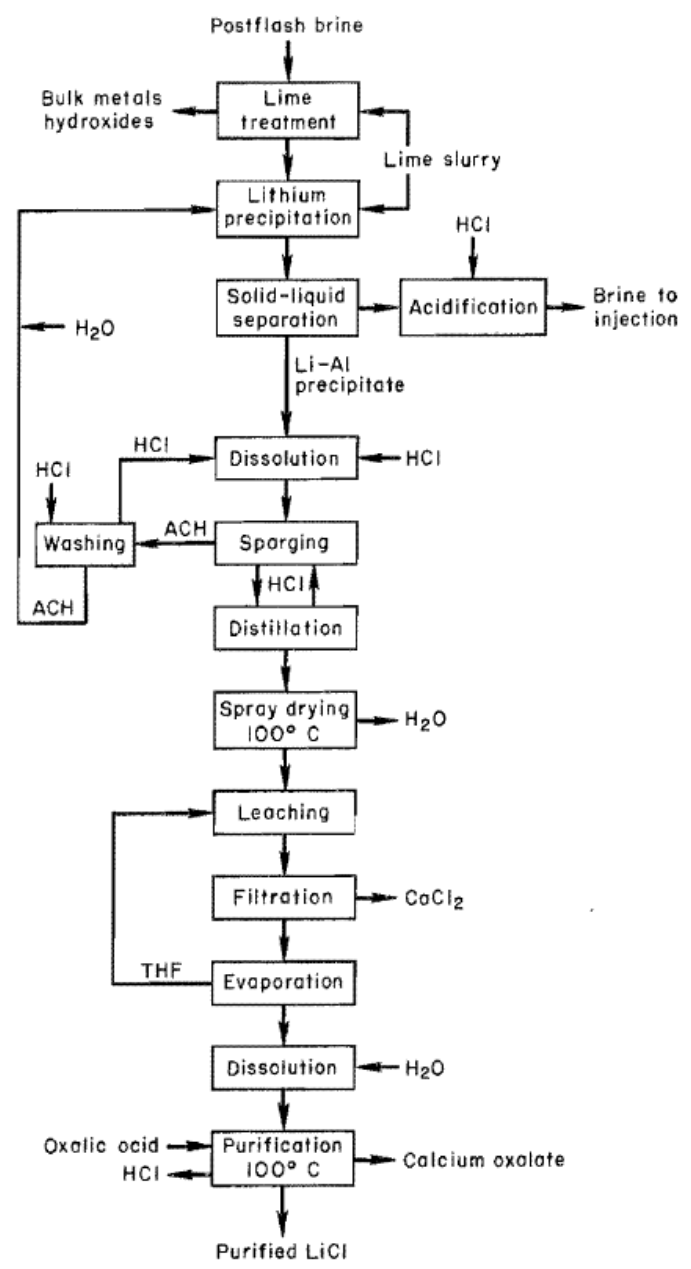

Figure 3. Lithium extraction process of Schultze and Bauer (1984)

Research on minerals recoverable from geothermal brines in the United States was further advanced by the private sector when Salton Sea geothermal operators began to explore opportunities to add revenue streams with minerals recovery, though these efforts were not initially focused on lithium. CalEnergy developed a process to recover zinc from geothermal fluid utilizing ion exchange, solvent extraction, electrowinning, and casting. After 10 months of running a pilot plant in 1998, CalEnergy planned to build a mineral recovery facility to process geothermal fluid from multiple power plants at a rate of 9 million $\mathrm{kg} / \mathrm{h}$ and capable of producing $30,000 \mathrm{mt}$ of $\mathrm{Zn}$ at $99.9 \%$ purity (Clutter 2000). Limited production began in 2002 and continued through 2004 before the project was shut down because of poor economic performance.

\subsection{DOE Support of Lithium Extraction from Geothermal Brines}

The U.S. Department of Energy Geothermal Technologies Office has supported multiple projects focused on extraction of lithium, and other minerals, from geothermal brines. Through the American Reinvestment and Recovery Act, DOE supported Simbol Inc.'s (also known as Simbol Mining and Simbol Materials) development of processes to mine lithium and other minerals from geothermal brines at Salton Sea, including deployment of a pilot mineral recovery plant at CalEnergy's Elmore plant that later moved to EnergySource's John L. Featherstone plant. 
Simbol's work continued through the DOE-funded project, DE-EE0002790: "Technologies for Extracting Valuable Metals and Compounds from Geothermal Fluids." The project focused on recovery of lithium, manganese, zinc, and potassium from Salton Sea brines and included investigation of new methods to manage silica and produce commercial products from geothermal brine (Harrison 2014) with continued, additional work made possible through funding from the California Energy Commission (PIR 10-059). The lithium-focused parts of these research efforts culminated in pilot tests using Salton Sea geothermal brine, and outcomes were deemed encouraging for advancing to commercial scale with specific advances noted in silica management, lithium extraction, purification, concentration, and conversion into lithium hydroxide and lithium carbonate products (see Appendix A for details; Harrison 2014 and 2015). Simbol's pilot demonstrations showed that $95 \%$ of lithium could be extracted as $\mathrm{LiCl}$ with sorbents utilizing lithium-aluminum double hydroxide chloride (LDH), and concentrated $\mathrm{LiCl}$ solution could be converted to $\mathrm{Li}_{2} \mathrm{CO}_{3}$ and $\mathrm{LiOH} \cdot \mathrm{H}_{2} \mathrm{O}$ (lithium hydroxide monohydrate, or LHM) end products with $90 \%$ yield (Harrison 2014). Unfortunately, Simbol's financing and business collapsed in 2015 , and detailed cost and performance data are not publicly available.

The evolving opportunity for commercial extraction of valuable minerals from geothermal brines was given a boost in 2014 when DOE's Geothermal Technologies Office introduced additional R\&D funding to support mineral recovery from geothermal brines. DOE-sponsored R\&D efforts focused on characterization of geothermal mineral resources and mineral recovery from geothermal brines-DE-FOA-0001016 in FY 2014 and DE-FOA-0001376 in FY 2016 - with primary focus on rare earth elements and lithium. Of the funded projects, two DE-FOA-0001016 projects focused on lithium extraction from geothermal brines (Ventura et al. 2016; Renew and Hansen 2017). Ventura et al. (2016) published results from their project, "Selective Recovery of Metals from Geothermal Brines," and Renew and Hansen (2017) published results from "Geothermal Thermoelectric Generation (G-TEG) with Integrated Temperature Driven Membrane Distillation and Novel Manganese Oxide for Lithium Extraction."

Renew and Hansen (2017) provide proof of concept for a lithium extraction process integrated with thermoelectric generation. The components of the process included silica removal by precipitation with iron, brine concentration with membrane distillation, nanofiltration to remove divalent cations, and manganese oxide adsorbents to extract and recover lithium. Details of the process are described in Appendix A. Renew and Hansen (2017) performed a techno-economic analysis that suggested the process would not be economically viable, particularly with respect to $\mathrm{Li}$ concentration $(150 \mathrm{mg} / \mathrm{L})$ and $\mathrm{Li}_{2} \mathrm{CO}_{3}(\$ 20,000 / \mathrm{mt})$ price sensitivity used in their study. Higher concentrations $(300 \mathrm{mg} / \mathrm{L})$, higher prices $(\$ 28,000 / \mathrm{mt})$, or reduced capital costs $(-27 \%)$ potentially could support project economics. From a technical perspective, the authors identified potential improvements that could improve economics, in particular improved membrane distillation flux performance, reduced lithium sorbent column size, reduced lithium sorbent usage, and increased operating period between regeneration cycles.

Ventura et al. (2016) examined feasibility of developing a new generation of ion-exchange resins based on metal-ion imprinted polymers for the separation of lithium and manganese from geothermal fluids. Lithium- and manganese-imprinted polymer beads, with the metal template preserved in the bead to accept the specific metal ions, were demonstrated in batch extractions and packed bed columns to be selective solid sorbents for extraction of lithium and manganese from a synthetic geothermal fluid. Details of the lithium extraction process are described in 
Appendix A. In a preliminary process cost assessment, the authors found their extraction processes to be economically viable. The main technical improvements identified for future work included increasing the capacity and selectivity of the sorbents with materials with higher lithium affinity and development of nanocomposite sorbents. Their work continued with funding from the California Energy Commission (see below; Ventura et al. 2018; 2020).

\section{Techno-Economic Analysis}

Lithium is an alkali metal that typically occurs in brine as $\mathrm{LiCl}$. A $\mathrm{LiCl}$ solution is concentrated and purified through various processes and is then converted to high-purity $\mathrm{Li}_{2} \mathrm{CO}_{3}$ and/or $\mathrm{LiOH} \cdot \mathrm{H}_{2} \mathrm{O}$ commercial products. A common way to describe contained lithium is by reporting lithium carbonate equivalent (LCE), and Table 2 shows conversion factors for expressing amounts of lithium in various species.

Table 2. Lithium Species Conversion Factors

\begin{tabular}{|c|c|c|c|c|}
\hline \multicolumn{2}{|c||}{} & \multicolumn{3}{|c|}{ Conversion Factors } \\
\hline Species & Molecular Weight $(\mathrm{g} / \mathrm{mol})$ & $\mathrm{Li}_{2} \mathrm{CO}_{3}$ & $\mathbf{L i C l}$ & $\mathbf{L i O H}-\mathrm{H}_{2} \mathrm{O}$ \\
\hline Lithium Carbonate $\left(\mathrm{Li}_{2} \mathrm{CO}_{3}\right)$ & 73.882 & 1.000 & 1.147 & 1.136 \\
\hline Lithium Chloride $(\mathrm{LiCl})$ & 42.384 & 0.872 & 1.000 & 0.990 \\
\hline Lithium Hydroxide Monohydrate $\left(\mathrm{LiOH}-\mathrm{H}_{2} \mathrm{O}\right)$ & 41.960 & 0.880 & 1.010 & 1.000 \\
\hline Lithium & 6.938 & 5.324 & 6.109 & 6.048 \\
\hline
\end{tabular}

Diverse DLE processes can be applied to extraction of lithium from geothermal brines, and the most advanced studies and pilot demonstrations in the United States have focused on adsorption and ion-exchange methods at the Salton Sea KGRA (Harrison 2014; Ventura et al. 2020; EnergySource Minerals 2021). Only Ventura et al. (2020) have reported an estimated cost of lithium production from Salton Sea brine (Section 4.2), so additional data from DLE projects exploiting other brine types are included to better inform cost estimates (Section 4.1). Cost estimates typically focus on reported OPEX (\$/mt lithium product), and positive Internal Rate of Return (IRR) suggests that the projects reviewed are economically feasible at modeled prices $>\$ 11,000 / \mathrm{mt} \mathrm{Li}_{2} \mathrm{CO}_{3}$ and $>\$ 12,267 / \mathrm{mt} \mathrm{LiOH} \cdot \mathrm{H}_{2} \mathrm{O}$ (see Table 3 below).

\subsection{Proposed Direct Lithium Extraction Projects}

Without cost and performance details from demonstration projects focused on Salton Sea geothermal brines or robust process modeling that is beyond the scope of this study, we must look primarily at bench-scale studies of lithium extraction from geothermal brines that have been scaled up to estimate commercial-scale cost of production. In the present study, we are mainly limited to understanding techniques and costs made publicly available by companies with projects advanced to stages of development and investment that require formal reporting to stock exchanges in Canada and Australia. These projects are focused on geothermal, salar, oilfield, and evaporite brines, all of which are informative for estimating costs of lithium extraction from geothermal brines. Ultimately, a specific geothermal fluid will require a best-fit lithium extraction process, or combination of processes, based on fluid composition and physical and chemical requirements related to power generation and reservoir management. 
Ventura et al. (2016) report an estimated lithium production cost of $\$ 3,845 / \mathrm{mt}$ LCE using ionimprinted polymer sorbents and synthetic Salton Sea brine (Table 2; Appendix A). This study is possibly the most relevant to consideration of the cost of lithium extraction from Salton Sea brines because it describes experiments with Salton Sea brine compositions. Absent cost and performance data from the Simbol pilot projects, understanding of the performance and costs of DLE are limited to modeling that scales up bench- and mini-pilot-scale experimental results. Geothermal operators at the Salton Sea are planning lithium extraction at various scales, and some of these companies have communicated cost estimates to the public.

Outside of the United States, hybrid power production and lithium extraction from geothermal brines are proposed in the Upper Rhine Valley of southwestern Germany. Three operating power plants demonstrate the potential for geothermal power generation, while bench-scale studies of sorbents and Upper Rhine Valley geothermal fluid indicate the potential to extract $>90 \%$ of lithium from brine containing $181 \mathrm{mg} / \mathrm{kg}$ lithium (Vulcan Energy Resources 2020).

The companies discussed herein have submitted Preliminary Economic Assessments (PEA) for their DLE projects to Canadian stock exchanges (publicly available) or Pre-Feasibility Studies (PFS) to Australian stock exchanges (public availability determined by company boards of directors). Canada's National Instrument 43-101 provides for a Qualified Person applying standards and best practices in the reporting of mineral resources, including assessment of the methods and economics of their extraction, and Australian exchanges require compliance (Joint Ore Reserves Committee [JORC] standards) with similar requirements. A PEA is an economic analysis of the potential viability of a resource extraction that is meant to inform markets and investors about the economic potential of the project; however, a PEA or PFS is not a guarantee of project success. Some of the oilfield and evaporite brine projects have advanced to pilot scale and provide confidence in the technical feasibility of DLE, and with reasonable assumptions, the PEA and PFS cost estimates can provide guidance for estimating costs of lithium extraction from geothermal brines. Table 3 summarizes reported DLE economics for geothermal, oilfield, evaporite, and salar brine types. 
Table 3. Summary of DLE Project Economics

\begin{tabular}{|c|c|c|c|c|c|c|c|}
\hline Company & SRI International & Vulcan Energy Resources & Standard Lithium & E3 Metals Corp & Anson Resources & Pure Energy Minerals & Lake Resources \\
\hline Project & Salton Sea & Upper Rhine Valley & Lanxess Smackover & Clearwater & Paradox Stage 3 (Li)* & Clayton Valley & Kachi \\
\hline Location & California, USA & SW Germany & Arkansas, USA & Alberta, Canada & Utah, USA & Nevada, USA & Argentina \\
\hline Document & DOE, CEC reports & PFS & PEA & PEA & PEA & PEA & PFS \\
\hline Brine type & Geothermal & Geothermal & Evaporite (Br tail brine) & Oilfield & Evaporite & Evaporite & Salar \\
\hline Resource $(1,000 \mathrm{~kg}$ LCE) & NA & $15,850,000$ & $3,140,000$ & $2,200,000$ & 192,000 & 217,700 & $1,010,000$ \\
\hline Lithium concentration (mg/L) & 400 & 181 & 168 & 74.6 & $100-500$ & $65-221$ & 289 \\
\hline Production (mt/yr) & $20,000 * *$ & 40,000 & 20,900 & 20,000 & 15,000 & 11,500 & 25,500 \\
\hline Production cost $(\$ / \mathrm{mt})$ & 3,845 & $3,217 * * *$ & 4,319 & $3,656 * * * *$ & 4,545 & $3,217 * * * * *$ & 4,178 \\
\hline $\operatorname{CAPEX}(\$ 1,000)$ & 52,300 & $1,287,600$ & 437,162 & 602,000 & 120,000 & 358,601 & 544,000 \\
\hline OPEX $(\$ 1,000 / y r)$ & 76,900 & 128,688 & 90,259 & 73,200 & 68,180 & 36,516 & 106,539 \\
\hline Modeled product price $(\$ / \mathrm{mt})$ & 12,000 & 14,925 & 13,550 & 15,160 & 13,000 & 12,267 & 11,000 \\
\hline Pre-tax IRR (\%) & 268 & 31 & 41.8 & 32 & 106 & 24 & 25 \\
\hline Technology & lon exchange & Adsorption & lon exchange & Ion exchange & Ion exchange & Solvent extraction $* * * * * *$ & Ion exchange \\
\hline Lithium recovery & $90 \%$ & $90 \%$ & $90 \%$ & $>90 \%$ & $75 \%$ & $90 \%$ & $83.20 \%$ \\
\hline Comments & $\begin{array}{l}\quad \text { Li2CO3 } \\
\text { Bench-scale testing } \\
\text { and ASPEN modeling } \\
\text { of hybrid sorbent } \\
\text { with nanostructured } \\
\text { manganese oxide } \\
\text { embedded within Li- } \\
\text { imprinted polymer } \\
\text { beads using synthetic } \\
\text { brine. }\end{array}$ & \begin{tabular}{l}
\multicolumn{1}{c}{$\mathrm{LiOH} \cdot \mathrm{H} 2 \mathrm{O}$} \\
Known geothermal \\
resource with measured \\
chemistry and \\
temperature. Bench-scale \\
testing of two \\
commercially available \\
adsorbents using Upper \\
Rhine Valley brine.
\end{tabular} & $\begin{array}{l}\quad \mathrm{Li} 2 \mathrm{CO} 3 \\
\text { Bench- and mini-pilot- } \\
\text { scale confirmation of } \\
\text { process using ceramic } \\
\text { adsorbent and } \\
\text { crystallization process } \\
\text { to convert } \\
\text { concentrated LiCl into } \\
\text { high-purity Li2CO3. }\end{array}$ & $\begin{array}{l}\quad \mathrm{LiOH} \cdot \mathrm{H} 2 \mathrm{O} \\
\text { Bench-scale } \\
\text { testing } \\
\text { demonstrated } \\
\text { high Li selectivity } \\
\text { and recovery. Full } \\
\text { process yet to be } \\
\text { tested. }\end{array}$ & \begin{tabular}{l}
\multicolumn{1}{c}{$\mathrm{Li2 \textrm {CO } 3}$} \\
Multi-stage \\
development with \\
stage 3 producing \\
$60,000 \mathrm{mt} / \mathrm{yr} \mathrm{NaBr}$ \\
and $15,000 \mathrm{mt} / \mathrm{yr}$ \\
Li2CO3. Production \\
cost reported as All- \\
in Sustaining Cost.
\end{tabular} & $\begin{array}{l}\quad \mathrm{LiOH} \cdot \mathrm{H} 2 \mathrm{O} \\
\text { Bench-scale testing of } \\
\text { brine and synthetic } \\
\text { equivalents informed the } \\
\text { solvent extraction } \\
\text { process developed by } \\
\text { Tenova. }\end{array}$ & \begin{tabular}{l}
\multicolumn{1}{c}{$\mathrm{Li} 2 \mathrm{CO} 3$} \\
Nano-coated, \\
porous ion \\
exchange beads, \\
tailored \\
composition, and \\
continuous \\
column process.
\end{tabular} \\
\hline \multicolumn{8}{|c|}{$\begin{array}{l}\text { *Estimated based on lithium component of operations; Phase } 3 \text { PEA retracted in June } 2020 \text { due to amounts of inferred resources. This does not affect estimates of CAPEX and OPEX. } \\
\text { **Estimated commercial production with costs and performance informed by bench-scale experiments and ASPEN modeling (Ventura et al. 2020). }\end{array}$} \\
\hline \multicolumn{8}{|c|}{ ****Euro to USD exchange rate $1.2 ; \$ 3,656 / \mathrm{mt} \mathrm{Li2CO3.}$} \\
\hline \multicolumn{8}{|l|}{$* * * * \$ 4,155 / \mathrm{mt} \mathrm{Li2CO3}$} \\
\hline$* * * * \$ 3$ & & & & & & & \\
\hline
\end{tabular}


Some of the DLE projects (Table 3; Appendix A) report detailed operating expenses (OPEX). These provide information about specific parts of the costs for DLE (Tables 4 through 7).

Table 4. Standard Lithium's Estimated Annual OPEX in U.S. Dollars for the Smackover Evaporite Brine DLE Project

\begin{tabular}{|c|c|c|c|c|c|c|}
\hline Description & \multicolumn{2}{|c|}{ Phase 1} & \multicolumn{2}{|r|}{ Phase 2} & \multicolumn{2}{|r|}{ Phase 3} \\
\hline $\mathrm{Li}_{2} \mathrm{CO}_{3}(\mathrm{mt} / \mathrm{yr})$ & & 9,700 & & 8,200 & & 3,000 \\
\hline Manpower & $\$$ & $3,745,000$ & $\$$ & $5,680,000$ & $\$$ & $6,710,000$ \\
\hline Electrical power & $\$$ & $4,040,000$ & $\$$ & $7,306,000$ & $\$$ & $9,097,000$ \\
\hline Reagents and consumables & $\$$ & $30,138,000$ & $\$$ & $55,615,000$ & $\$$ & $64,936,000$ \\
\hline Water & $\$$ & 496,000 & $\$$ & 916,000 & $\$$ & $1,070,000$ \\
\hline Natural gas & $\$$ & 582,000 & $\$$ & $1,074,000$ & $\$$ & $1,254,000$ \\
\hline Miscellaneous direct expenditures & $\$$ & 605,000 & $\$$ & $1,098,000$ & $\$$ & $1,299,000$ \\
\hline
\end{tabular}

Table 5. E3 Metal Corp's Estimated OPEX in Canadian Dollars for the Clearwater Oilfield Brine DLE Project

\begin{tabular}{l|lr}
\hline Description & $\$ / \mathrm{mt}$ LHM \\
\hline Reagents/chemicals & $\$$ & $1,642.00$ \\
\hline Electrical power & $\$$ & $1,779.00$ \\
Well servicing & $\$$ & 118.00 \\
Maintenance and service for pre-tretment & & \\
and injection & $\$$ & 15.00 \\
Lithium extraction & $\$$ & 756.00 \\
\hline Solids disposal & $\$$ & 37.00 \\
Natural gas & $\$$ & 53.00 \\
\hline Manpower & $\$$ & 336.00 \\
\hline Product transport & $\$$ & 75.00 \\
\hline Land lease & $\$$ & 26.00 \\
\hline Administration/selling & $\$$ & 100.00 \\
\hline TOTAL (Canadian dollars) & $\$$ & $4,937.00$ \\
\hline TOTAL (U.S. dollars) & $\$$ & $3,657.00$ \\
& &
\end{tabular}


Table 6. Anson Resources' Estimated Annual OPEX for the Paradox Basin DLE Project

\begin{tabular}{l|lr}
\multicolumn{1}{c|}{ Phase 3: Lithium* } & \multicolumn{2}{c}{$\$ /$ year } \\
\hline Raw materials & $\$$ & $25,993,603$ \\
\hline Utilities & $\$$ & $35,195,571$ \\
\hline Manpower & $\$$ & $6,991,012$ \\
TOTAL & $\$$ & $68,180,186$
\end{tabular}

* Li extraction OPEX is separated from reported combined $\mathrm{Br}$ and Li operations. Phase 3 estimates were retracted owing to large inferred resources, but cost estimates remain valid.

Table 7. Lake Resources' Estimated Annual and Specific OPEX for the Kachi DLE Project

\begin{tabular}{l|rr|rr}
\multicolumn{1}{c|}{ Description } & & \multicolumn{1}{c}{ Cost per year } & Cost per metric ton LCE \\
\hline Labor & $\$$ & $10,900,000$ & $\$$ & 394 \\
\hline Utilities (electric, gas, water) & $\$$ & $42,100,000$ & $\$$ & 1,677 \\
Reagents & $\$$ & $16,100,000$ & $\$$ & 630 \\
Consumables & $\$$ & $22,400,000$ & $\$$ & 876 \\
Maintenance & $\$$ & $4,700,000$ & $\$$ & 185 \\
General and administration & $\$$ & $10,600,000$ & $\$$ & 416 \\
\hline TOTAL & $\$$ & $106,800,000$ & $\$$ & $4,178$.
\end{tabular}

Tables 3 through 7 summarize the public cost information related to DLE from brines. Each project has unique physical, chemical, and economic requirements that help determine the optimized DLE process. Geothermal brines also have unique brine pre-treatments required for power generation, and the power generation process influences the physical and chemical properties of injection fluid that is the source brine for lithium extraction operations. Power generation processes can benefit lithium extraction with the potential to provide power, heat, and water for downstream operations. Care must be taken that after lithium extraction the fluids retain physical and chemical properties like the original injectate, so they do not negatively impact injection well and reservoir performance.

\subsection{DLE from Salton Sea Geothermal Brines}

Available data and estimates of costs for lithium extraction from geothermal brines are limited, and this report is focused on available data without new process modeling efforts. Generally, the primary differences between non-geothermal brine processes and those applied to geothermal brine at the Salton Sea are required pre-processing to manage silica, iron and other metals and, if required, post-processing to ensure appropriate physical and chemical properties of injected tail brine to prevent adverse impacts on the reservoir that can negatively impact power generation. Salton Sea plant operators have decades of experience managing pre-processing to enable power generation and post-processing to prevent scaling of injection wells.

Ventura et al. (2020) estimated costs to extract lithium based on bench-scale experiments with Salton Sea brine and process modeling simulations. Some details of the Simbol pilot project at 
the Salton Sea are available (Harrison 2014). EnergySource and Berkshire Hathaway have operating power plants at the Salton Sea and are planning lithium extraction demonstrations. Limited public information is available; however, detailed U.S. patent documents (e.g., Marston and Garska 2019) describe in detail the process proposed by EnergySource. Information from these Salton-Sea-focused projects together provide a template for a potential process for commercial lithium extraction from geothermal brine and expected costs.

Lithium extraction at the Salton Sea will exploit lithium-rich fluids downstream from the power generation process. Figure 4 is a schematic of the power generation process for a typical Salton Sea power plant (Featherstone et al. 1995). Lithium extraction benefits from crystallizer and clarifier processes to remove silica and iron as pre-treatment for the power generation process. The feedstock for lithium extraction comes from downstream of the secondary clarifier.

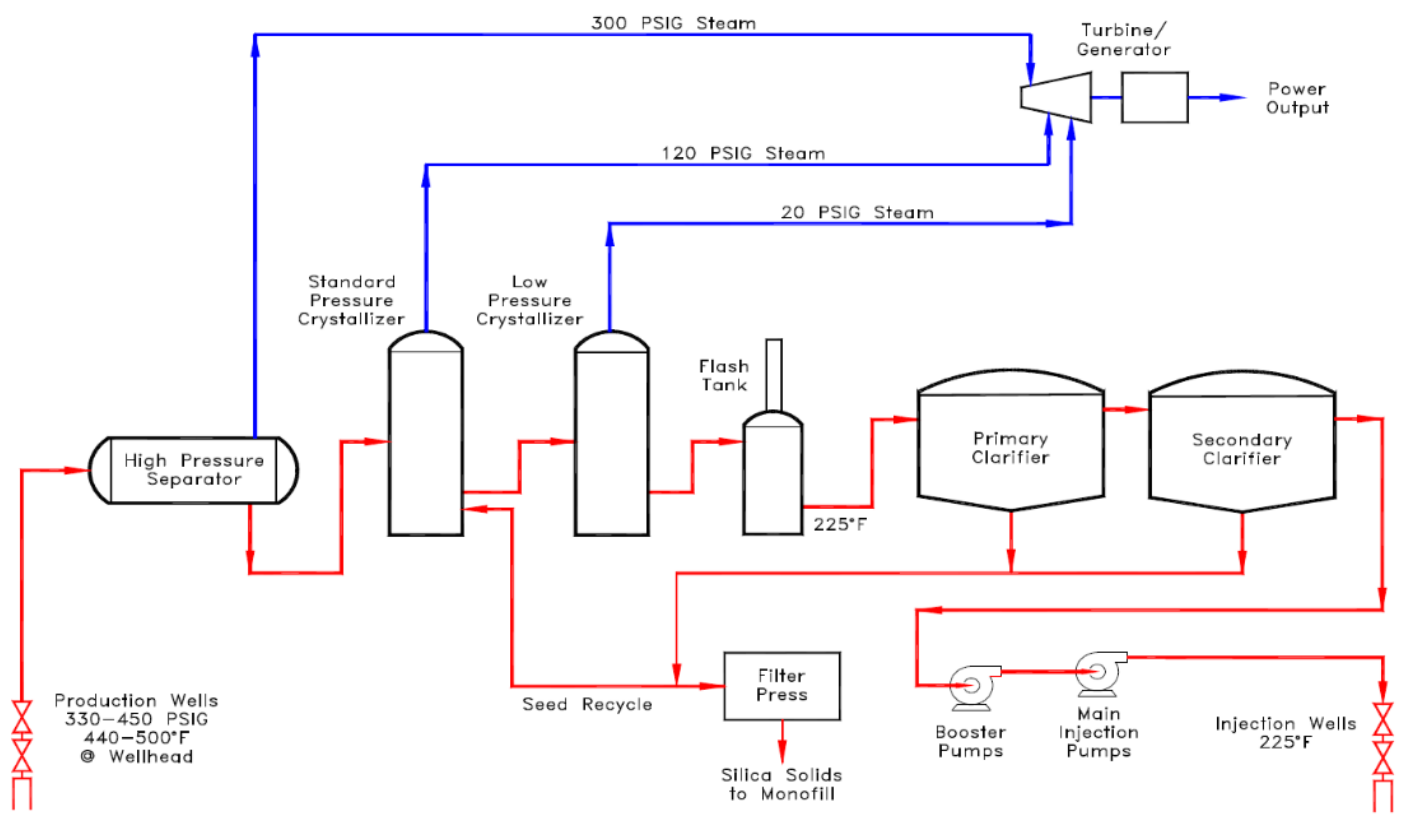

Figure 4. Simple schematic of power generation process at Salton Sea

Figure from Featherstone et al. (1995)

Simbol (Harrison 2014), SRI International (Ventura et al. 2020), EnergySource (Marston and Garska 2019), and Berkshire Hathaway Energy (BHER Minerals 2020) have proposed lithiumselective sorbents for lithium extraction from Salton Sea geothermal brines. Estimated costs based on detailed process modeling (Ventura et al. 2020) are $\$ 3,845 / \mathrm{mt} \mathrm{LCE}$, and Berkshire Hathaway Energy has a target price for their demonstration of $<\$ 4,000 / \mathrm{mt} \mathrm{LCE}$. EnergySource has not publicly provided costs, but their reported project development and construction costs ( $\sim 350$ million), combined with internal rate of return in the range reported by companies proposing DLE (Table 3) and projected $\mathrm{Li}_{2} \mathrm{CO}_{3}$ price of $\$ 12,000 / \mathrm{mt}$, suggests a cost near $\$ 4,000 / \mathrm{mt} \mathrm{LCE}$ for planned production of 16,500 mt LCE per year (EnergySource 2021). Details provided next are based on EnergySource's detailed process descriptions from patent applications (Marston and Garska 2019). Though other processes that might be commercialized at the Salton Sea will vary in design (e.g., BHER Minerals 2020), they will share many of the same process steps and likely have costs near $\$ 4,000 / \mathrm{mt}$ LCE. The impact of EnergySource's proposed project, and the impact potential of the Salton Sea KGRA in total, is significant. 
EnergySource's proposed 16,500 mt/yr LCE output is equivalent to current U.S. annual demand reported by the USGS (<16,000 mt LCE; Jaskula 2020), and it represents only part of the Salton Sea lithium resource (15 million mt; Chao 2020). Salton Sea geothermal power plants had throughput in 2019 equivalent to $127,750 \mathrm{mt}$ LCE $(121,308,148 \mathrm{mt}$ with average lithium concentration of $200 \mathrm{mg} / \mathrm{L}$ ).

Figure 5 shows the process steps for production of lithium carbonate based on EnergySource's patented process (Marston and Garska 2019). Figure 6 shows and describes the details of the continuous countercurrent adsorption and desorption part of the lithium extraction process.

EnergySource Lithium Carbonate Production Process

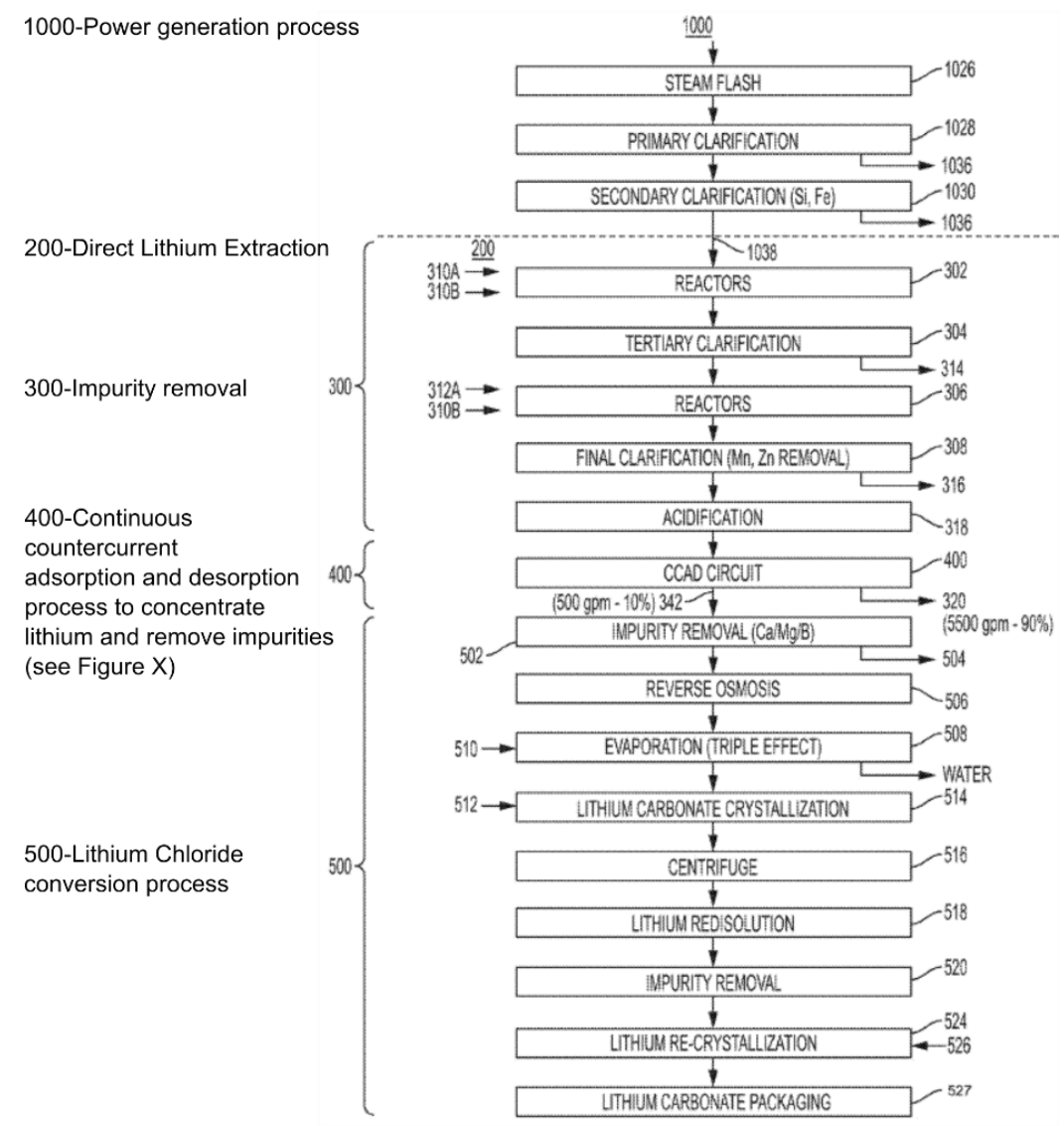

Description of process steps:

1000: liquid brine from power plant operations; 1026: atmospheric flash of post-crystallizer brine slurry; 1028: reactor clarifier precipitates silica; 1030: secondary clarifier removes suspended solids;

1036: liquid separated from solids via horizontal belt filter with vacuum and filter cloth with $\mathrm{pH} 1 \mathrm{HCl}$ acid wash to remove lead and $\mathrm{pH} 9.5$ condensate wash to remove $\mathrm{HCl}$;

200: DLE process;

1038: polished brine from secondary clarifier;

300: impurity removal; 302: reaction tank to facilitate removal of iron and silica;

310A: limestone slurried with brine to maintain $\mathrm{pH}$ 5.5; 310B: air injection to oxidize iron;

304: clarifier with flocculent added to remove iron and silica; 314: Fe/silica filter cake;

306: secondary reactor tanks to facilitate metals removal (mainly $\mathrm{Zn}, \mathrm{Mn}$ );

312A: limestone slurried with brine to maintain $\mathrm{pH}$ 8; 310B: air injection to oxidize iron;

308: secondary clarifier precipitates $\mathrm{Zn}, \mathrm{Mn}$ oxide/hydroxides;

316: $\mathrm{Zn}, \mathrm{Mn}$ filter cake; $318-\mathrm{HCl}$ added to lower $\mathrm{pH}$ to 4.5-6; temperature $5 \mathrm{C}-100 \mathrm{C}$; 
320: residual brine returned for wellfield injection ( $5500 \mathrm{gpm}$ );

342: concentrated LiCl product stream with $90 \%-97 \%$ of lithium from raw brine and $99.9 \%$ of impurities removed;

502: $\mathrm{Ca}$ and $\mathrm{Mg}$ precipitated with addition of sodium hydroxide;

504: $\mathrm{Ca}$ and $\mathrm{Mg}$ filter cake removed from $\mathrm{LiCl}$ stream;

506: $\mathrm{LiCl}$ concentration with reverse osmosis membrane $(\sim 3,000$ to $5,000 \mathrm{mg} / \mathrm{kg} \mathrm{Li})$;

508: evaporator to remove water and further concentrate $\mathrm{LiCl}(\sim 5,000$ to $30,000 \mathrm{mg} / \mathrm{kg} \mathrm{Li})$;

510: evaporator steam from geothermal operations;

512: addition of sodium carbonate to precipitate lithium carbonate (514);

516: water separated from lithium carbonate with centrifuge;

518: lithium carbonate redissolved; 520: final impurity removal;

522: recrystallized lithium carbonate with addition of $\mathrm{CO}_{2}(524)$;

527: packaging of final lithium carbonate product.

Figure 5. Detailed process steps for production of lithium with ILiAD technology EnergySource (2021)

\section{Continuous Countercurrent Adsorption and Desorption (CCAD)}
A. adsorption displacement
B. adsorption loading
C. entrainment rejection
D. elution

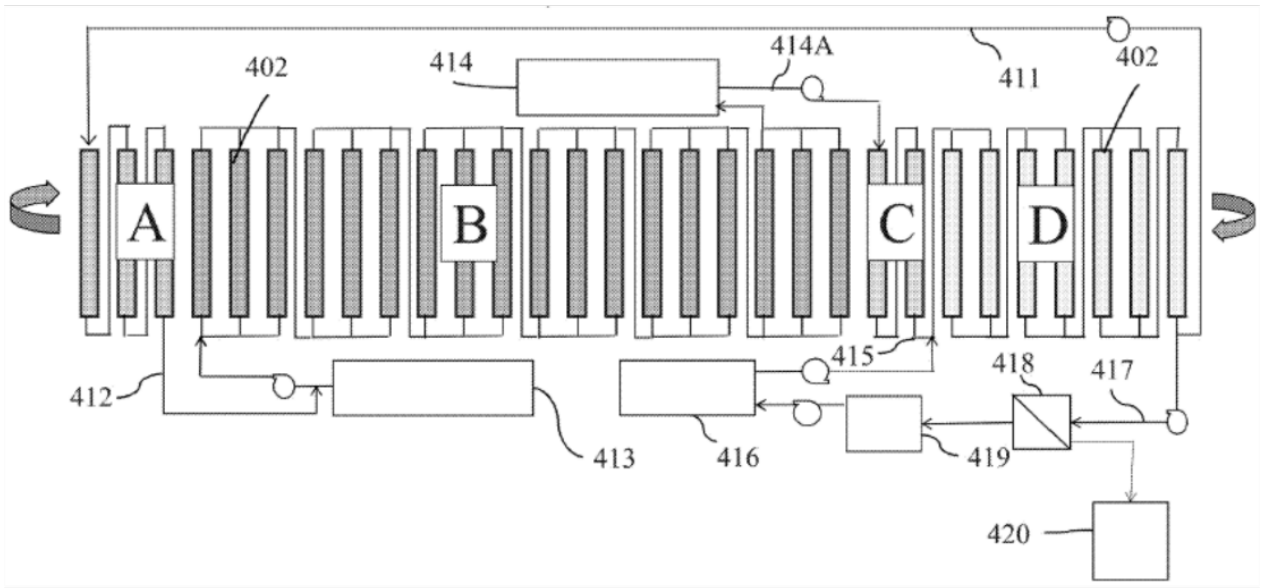

402: lithium selective adsorbtion beds cycle continuously through $A B C D$ process zones

411: remove residual brine and salts from elution zone with portion of $\mathrm{LiCl}$ product stream

412: elution volume of feed brine removed

413: polished feedstock brine pumped into adsorption loading zone (B)

414: depleted brine to raffinate

414A: raffinate pumped to entrainment rejection $(\mathrm{C})$ to displace latent eluate solution

415: latent eluate solution entrained in transition from lentrainment rejection (C) to elution (D)

416: eluant (stripping solution) pumped countercurrent to adsorption advance in elution zone (D)

417: $\mathrm{LiCl}$ product stream with 10-20x Li concentration of eluant and $99.9 \%$ of impurities removed

418: optional reverse osmosis or nanofiltration membrane to further concentrate $\mathrm{Li}$

419: recycled to make up eluant (416)

420: further Li-concentrated product stream

Figure 6. Details of the continuous countercurrent adsorption and desorption process

Marston and Garska (2019)

There is no detailed public information regarding modification of fluid after lithium extraction and prior to injection. With many of the highly concentrated species removed or partially removed during the lithium extraction process, composition of tail fluids is likely to be acceptable for injection. Materials and infrastructure are already in place at Salton Sea geothermal power plants if scale inhibition processes are required. The tail fluid will be cooler than the normal injection stream, and this could potentially affect reservoir temperatures if large 
volumes of cooled, post-lithium-extraction fluid are injected for many years. Also, it is unclear how a lithium-depleted brine will interact with the reservoir geology in terms of re-saturation with lithium before returning to production wells.

\subsection{Planned and Ongoing Demonstrations}

Multiple companies are pursuing DLE projects focused on geothermal and other brines (e.g., Table 3); however, the most important demonstrations for U.S. lithium production are focused on Salton Sea brines. One of the most recently announced projects is a demonstration at the Salton Sea that began in 2020 with financial support from California Energy Commission through their EPIC program (BHER Minerals 2020). The demonstration facility will be sited at an existing geothermal power plant, with the project managed by BHER Minerals (wholly owned subsidiary of Berkshire Hathaway Energy). The project aims to process $100 \mathrm{gpm}(378 \mathrm{~L} / \mathrm{min})$ of geothermal injectate using an ion-exchange process to extract $>85 \%$ of the lithium at a cost $<\$ 4,000 / \mathrm{mt} \mathrm{LCE}$ while restricting water use to less than $190 \mathrm{~m}^{3} / \mathrm{mt} \mathrm{Li}_{2} \mathrm{CO}_{3}$ and showing potential for a 5-year payback for a commercial-scale facility.

As described previously, EnergySource is planning to build a lithium extraction facility at their Featherstone power plant, with construction starting in 2021 and operations beginning in 2023 (EnergySource 2021). They have reported successful completion of pilot testing of their patented Integrated Lithium Adsorption Desorption (ILiAD) technology, which combines lithiumselective sorbent with continuous bed processing. Pilot testing demonstrated monovalent and divalent removal $>99.5 \%$ and lithium recovery $>90 \%$ (Figure 7 ).

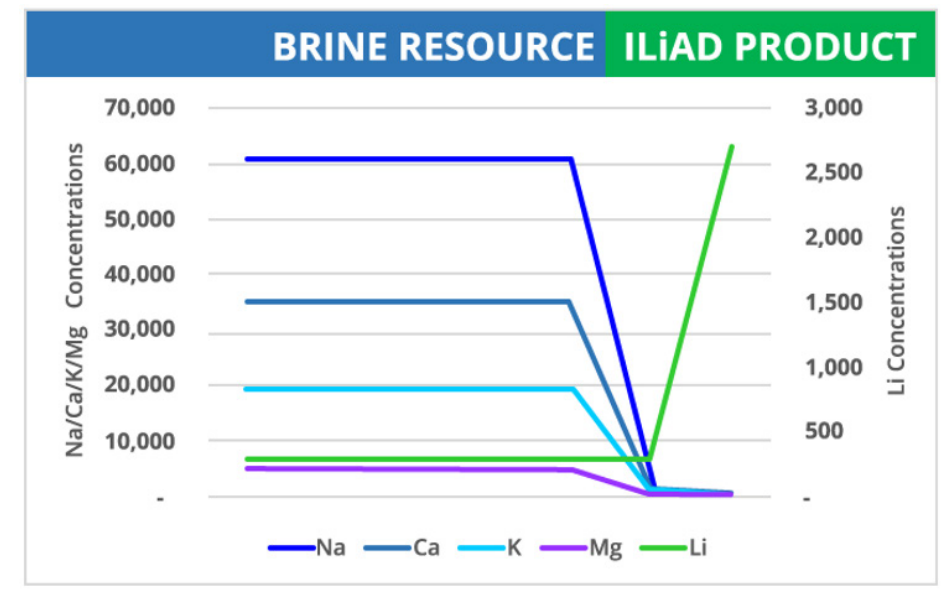

Figure 7. Lithium selectivity based on pilot testing of ILiAD technology

EnergySource (2021)

Controlled Thermal Resources (CTR) is planning commercial development of a hybrid geothermal power-lithium extraction operation at their Hell's Kitchen project. The current plan is for a 49.9-MW power plant and 20,000 $\mathrm{mt} / \mathrm{yr}$ lithium hydroxide production with construction potentially beginning in 2022 and operations beginning in 2023. CTR is designing a brine pretreatment process to be tested at pilot scale with funding support from California Energy Commission, along with testing of a novel process to remove silica called micropillar enabled particle separation (CTR 2020a; 2020b). 
It is unknown when and if detailed cost and performance data might become available from Simbol's pilot-scale demonstrations, but those data could further inform future lithium extraction efforts at Salton Sea.

\subsection{Future Considerations}

Future techno-economic analysis will benefit from detailed performance and cost data, ideally from pilot- and commercial-scale demonstrations. Additionally, robust modeling of lithium extraction from geothermal brines requires explicit process details, many of which are proprietary. There are detailed patent documents (e.g., EnergySource Minerals) available such that it might be possible to create a robust publicly available process model to understand performance and cost in greater detail; however, there is no single model to apply to all geothermal brines or even to different brine and power plant operations in the Salton Sea KGRA. Each will be unique to the specific physical and chemical conditions of brine and lithium extraction \pm power generation operations. Despite that, the range of brine types and lithium extraction processes reviewed herein suggest an OPEX near $\$ 4,000 / \mathrm{mt}$ LCE is achievable with modeled prices assumed to be $>\$ 11,000 / \mathrm{mt} \mathrm{Li}_{2} \mathrm{CO}_{3}$ and $>\$ 12,267 / \mathrm{mt} \mathrm{LiOH} \cdot \mathrm{H} 2 \mathrm{O}$ (Table 3). These prices are within the range of spot market prices since mid-2018, and increased lithium demand is expected in the future (Chao 2020).

Future potential process improvements involve increasing lithium selectivity relative to competing ions, increasing operating cycles between regeneration and replacement, lowering costs of sorbent and solvent manufacturing, and reducing energy and material requirements. The most important information related to economics and commercialization will likely be coming from demonstrations planned or underway at the Salton Sea.

Beyond demonstrations at Salton Sea, there is important research ongoing at laboratory scale. The most recent review of lithium extraction techniques is by Stringfellow and Dobson (2021), which provides descriptions and extensive documentation of methods being investigated by researchers (Table 8). Several of the techniques they review are discussed here to provide details of some of the more promising research completed and underway that is applicable to lithium extraction from geothermal brines. Stringfellow and Dobson (2021) report that lithium extraction with inorganic molecular sieve ion-exchange sorbents is the most developed technology and note that sorbent selectivity, sorbent tolerance for interfering ions, and purity of extracted lithium are the main cost drivers. They also note that large-scale, expensive demonstration projects are necessary to advance lithium extraction from geothermal brines toward commercialization, highlighting the importance of planned demonstrations at the Salton Sea and the data that will be generated from those projects. 


\section{Table 8. Techniques for Extraction of Lithium from Brines That Show the Breadth of Recent Research Efforts}

Stringfellow and Dobson (2021)

Direct Lithium Extraction Techniques
Precipitation
Organic sorbents
Organic ion-exchange resins
lon-imprinted polymers and other organic sorbents
Inorganic sorbents
Aluminum hydroxides
Manganese oxides
Titanium oxides
Other inorganic sorbents (various metal oxides)
Organic solvents
Crown ethers
Multicomponent
$\quad$ Extractant, co-extractant, diluent
Alternative diluents -ionic liquids, supercritical $\mathrm{CO}_{2}$
Supported liquid membranes
Membranes
Reverse osmosis
Nanofiltration
Electrochemical separation
Clectrodialysis
Combination with membrane and ion-exchange processes

Ling et al. (2018) reviewed techniques for lithium extraction from brines, focusing on sorbent, membrane, and precipitation techniques. For adsorption and ion exchange processes, spinel lithium manganese oxide (Li-Mn-O), spinel lithium titanium oxide (Li-Ti-O), and LDH $\left(\mathrm{LiCl} \cdot 2 \mathrm{Al}(\mathrm{OH})_{3}\right)$ have been identified as potential sorbents for lithium extraction. Lithium manganese oxides are synthesized and transformed into ion sieves by exchanging $\mathrm{Li}^{+}$for $\mathrm{H}^{+}$with the general formula $\mathrm{MnO}_{2} \cdot \mathrm{xH}_{2} \mathrm{O}$. Though they exhibit high capacity and selectivity, the acid required for sorbent regeneration, which can be produced during the lithium-ion exchange process, causes dissolution of $\mathrm{Mn}^{+}$and degradation of the sorbent. Titanium-oxide-based sorbents are advantageous because they have similar performance as manganese-oxide-based sorbents while being resistant to acid. Synthesized lithium titanate $\left(\mathrm{Li}_{2} \mathrm{TiO}_{3}\right)$ is the precursor for hydrated titanium oxide $\left(\mathrm{H}_{2} \mathrm{TiO}_{3}\right)$ sorbent, which has high lithium capacity and selectivity, despite studies that document some co-adsorbed sodium, potassium, magnesium, and calcium at non-negligible levels (Chitrakar et al. 2014). Other Li-Mn-O and Li-Ti-O chemistries have been explored with positive results. LDHs have slightly lower capacity but good selectivity, are relatively inexpensive to regenerate, and are stable through many cycles. Bench column experiments with LDH have shown high selectivity for lithium relative to competing ions, and LDH sorbents are low cost and environmentally benign without consuming reagent chemicals or producing secondary waste. Similar to the conclusions of Stringfellow and Dobson (2021), Paranthanam et al. (2017) reported that further improvements can be made in the quality of sorbent materials related to recovery efficiency, lithium capacity, selectivity relative to other competing bulk ions, and stability. 
The application of ionic liquids for solvent extraction shows promise for developing highlithium-affinity and highly efficient extraction processes (Yang et al. 2019). Established commercial solvent extraction expertise (e.g., Tenova) is also being directed toward advancing the technique's application to lithium extraction from brines. If inexpensive and sustainable chemistries can be developed, solvent extraction may be particularly suitable for geothermal brines with modest lithium concentrations (e.g., most brines outside the Salton Sea).

Mixed matrix membranes have been developed comprising polymers and metal organic framework nanoparticles formed into thin films that can separate lithium from monovalent ions in high-salinity brines at high rates, efficiency, and selectivity (Zhang et al. 2018). Chromatography is a proven technology in industrial applications for chemical separations, and researchers at NREL have recently begun investigating application of simulated moving bed chromatography to extraction of lithium and other materials from brines (Karp 2019). In this application, salts present in a brine feed, such as $\mathrm{LiCl}$, and pass over a zwitterionic stationary phase using fresh water as the eluent. Each salt intercalates with the zwitterionic group on the stationary phase and is slowed as it moves downward through the column. The salt movements down the column are slowed at different rates depending on their Van der Waals radius, charge, and solubility so that as the salts move through the stationary phase, they separate based on their differing affinities for the stationary phase.

Based on the available public data, general recommendations can be made with respect to optimization and continued development of DLE technologies for processing of geothermal brines at commercial scale.

- A variety of DLE processes and brine types have estimated OPEX near $\$ 4,000 / \mathrm{mt} \mathrm{LCE}$ (Table 3). If that is a reasonable estimate, DLE adoption and deployment could advance rapidly once processes are demonstrated at scale with transparent reporting of performance and costs.

- Diversity of fluid physical and chemical properties and variations in operational conditions (e.g., plant rejection temperature) require lithium extraction processes to be uniquely tailored to the target geothermal reservoir and power plant.

- Stoichiometries of chemical reactions and combinations of reactions guide the application of DLE in terms of reagent and materials costs.

- Need for DLE process power and water is mitigated by the availability of on-site geothermal power, heat, and water (RO-processed condensate). This gives geothermal sites a potential advantage over other DLE brine targets.

- In addition to lithium, other valuable minerals could potentially be extracted from geothermal brines. Continued attention toward extraction of minerals that are complementary to or compatible with lithium extraction could enhance economic viability.

- Because of the high concentration of lithium, Salton Sea geothermal brines are an obvious target for DLE. Further research is needed to economically develop techniques for 
geothermal brines with low lithium concentrations typically seen in most geothermal reservoirs in the United States. Lithium extraction from Salton Sea brines will benefit from cost reductions associated with increased sorbent selectivity for lithium with respect to competing ions such as sodium, potassium, calcium, and magnesium and from decreased pre-treatment requirements.

There are other considerations to address with respect to long-term deployment of DLE technologies independent of improving the cost and efficiency of extraction. If it is presumed that operations will be co-located with geothermal power production, the potential effects of lithium extraction on geothermal reservoirs need to be investigated. Reservoir modeling will be necessary to understand the effects of potentially cooler injectate unless brine is heated after lithium extraction to power plant rejection temperature. Modeling of the interaction of $\mathrm{Li}$ depleted injectate with the geothermal reservoir is necessary to understand the process of lithium re-saturation. Fracture controlled permeability and hydrothermal alteration potentially limit injectate's contact with lithium-rich rocks (e.g., silicified selvages to permeable fractures). The reservoir residence time of injected fluid before it returns to a production well may limit the time for lithium re-saturation. Understanding of the distribution of lithium-bearing rocks in the reservoir will be necessary to optimize lithium re-saturation if production wells show declining concentrations of lithium over time. The distribution of lithium-bearing rocks in the reservoir might also contribute toward planning of well locations for new, hybrid geothermal powerlithium extraction developments.

\section{Summary}

Lithium has been identified as a U.S. critical material. Lithium-rich geothermal brines represent a vast, untapped resource that can potentially be developed into a robust domestic supply. The most likely resource to be developed is at California's Salton Sea, where geothermal brines contain up to $400 \mathrm{mg} / \mathrm{kg}$ lithium. DLE technologies represent a diverse array of techniques that might be deployed to extract lithium from brines, including Salton Sea geothermal brine, and these techniques present an opportunity to increase sustainability and reduce overall impacts when compared to traditional evaporative pond and hardrock mining methods for producing lithium.

Several projects are underway that plan to use DLE technologies to extract lithium from brines, including geothermal brines. The most lithium-rich geothermal brines in the United States are at the Salton Sea, and demonstrations have and are focused on ion-exchange sorbents as the best technique to mine lithium from Salton Sea fluids. Though public data do not include detailed costs and performance, pilot tests at the Salton Sea undertaken by Simbol and EnergySource in the 2010s represent the most advanced level attained along the path to commercialization of lithium extraction from geothermal brines in the United States. EnergySource is planning deployment at commercial scale based on the results of its lithium extraction pilot testing.

A range of research shows that a viable lithium extraction process must be tuned to the physical and chemical conditions of the exploited geothermal reservoir, and available public information suggests that production costs may be near $\$ 4,000 / \mathrm{mt} \mathrm{LCE}$. Three Salton Sea operators are pursuing lithium extraction commercialization, and these projects offer the potential to demonstrate whether commercialization is feasible. EnergySource and Controlled Thermal 
Resources are planning to develop commercial operations in the next few years, and Berkshire Hathaway Energy is pursuing a pilot demonstration. All are planning to deploy lithium-selective sorbent processes. Opportunity to reduce production costs may come from research focused on improved sorbent performance, improved process design and efficiency, and/or breakthroughs in performance of other DLE technologies.

Additional considerations beyond the specific cost and performance of lithium extraction processes relate to impacts of the tail fluid on the geothermal reservoir. Injectate after lithium removal might be cooler than the normal power plant rejection temperature. Re-saturation of the brine with lithium could be affected by injectate access to lithium-bearing rocks in the reservoir and by injectate residence time. Reservoir modeling combined with details of lithium distribution in the reservoir could clarify the importance of these potential impacts from lithium extraction from the geothermal brine. 


\section{References}

Bauman, W.C., and J.L. Burba III. 1995. "Recovery of lithium values from brines." U.S. Patent No. 5,389,349.

Bauman, W.C., and J. L. Burba III. 2001. "Composition for the recovery of lithium values from brine and process of making/using said composition.” U.S. Patent No. 6,280,693.

Berthold C.E., and D. H. Baker. 1976. "Lithium recovery from geothermal fluids.” In: Lithium Resources and requirements by the year. Berthold, C. E., and F. M. Stephens. 1978.

"Magmamax No. 1 Geothermal Brine Bulk Solids Precipitation Pilot Plant-Engineering Design." U.S. Bureau of Mines OFR, 127-78.

Blake, R. 1974. "Extracting minerals from geothermal brines: a literature study." U.S. Dept. of the Interior, Bureau of Mines.

BHER Minerals. 2020. "Salton Sea Geothermal Lithium Recovery Demonstration Project." California Energy Commission Agreement EPC-019-020.

https://www.energy.ca.gov/filebrowser/download/293

Burba III, J.L. 1985. “Crystalline 3-layer lithium aluminates.” U.S. Patent No. 4,540,509.

CalGEM. 2020. “Geothermal Production and Injection Data Maps: Salton Sea.” California Geologic Energy Management Division.

https://www.conservation.ca.gov/calgem/geothermal/manual/Pages/production.aspx

Chao, J. 2020. "Geothermal Brines Could Propel California's Green Economy." https://newscenter.lbl.gov/2020/08/05/geothermal-brines-could-propel-californias-greeneconomy/

Chitrakar, R., Y. Makita, K. Ooi, and A. Sonoda. 2014. "Lithium recovery from salt lake brine by $\mathrm{H}_{2} \mathrm{TiO}_{3}$." Dalton Transactions 43, no. 23: 8933-8939.

Christopher, D. H., M. Stewart, and J. Rice. 1975. "The recovery and separation of mineral values from geothermal brines." Research report.

Clutter, T. J. 2000. "Mining Economic Benefits from Geothermal Brine.” Quarterly Bulletin 21, no. 2: 1-3.

Controlled Thermal Resources. 2020a. "Hell's Kitchen Geothermal Lithium Extraction Pilot." California Energy Commission Agreement EPC-19-018.

https://www.energy.ca.gov/filebrowser/download/1599

Controlled Thermal Resources. 2020b. "Improved Silica Removal for Enhanced Geothermal Plant Performance.” California Energy Commission Agreement EPC-19-029.

https://www.energy.ca.gov/filebrowser/download/1799

Duyvesteyn, W.P.C. 1992. "Recovery of Base Metals from Geothermal Brines." Geothermics 21: 773-799. 
EnergySource Minerals. 2021. https://www.esminerals.com/project

Facada, Martim. 2019. "Global lithium supply developing at accelerating pace on growing demand." Fastmarkets MB. Accessed on December 30, 2020.

https://www.metalbulletin.com/Article/3868440/Global-lithium-supply-developing-at-

accelerating-pace-on-growing-demand.html

Fastmarkets. 2021. https://www.fastmarkets.com/commodities/industrial-minerals/lithium-pricespotlight.

Featherstone, J. L., S. Butler, and E. Bonham. 1995. "Comparison of crystallizer reactor clarifier and $\mathrm{pH}$ mod process technologies at the Salton Sea geothermal field." World Geothermal Congress 1995. Florence, Italy.

Flexer, V., C. F. Baspineiro, and C. I. Galli. 2018. "Lithium recovery from brines: A vital raw material for green energies with a potential environmental impact in its mining and processing." Science of the Total Environment 639: 1188-1204.

Fortier, S. M., N. T. Nassar, G. W. Lederer, J. Brainard, J. Gambogi, and E. A. McCullough. 2018. "Draft critical mineral list - Summary of methodology and background information-U.S. Geological Survey technical input document in response to Secretarial Order No. 3359." U.S. Geological Survey Open-File Report 2018-1021. https://doi.org/10.3133/ofr20181021.

Grant, A. 2020. "Disruption or Evolution?" Benchmark Q1 Review 2020: Lithium Extraction: $46-52$.

Harrison, S. 2014. Technologies for extracting valuable metals and compounds from geothermal fluids. California Energy Commission. Publication Number: CEC-500-2015-023.

Jaskula, Brian. 2020. "Mineral Commodity Summaries: Lithium.” U.S. Geological Survey. https://pubs.usgs.gov/periodicals/mcs2020/mcs2020-lithium.pdf

Karp, E. 2019. "Hybrid Thermal-Chromatographic System for Simultaneous Mineral Purification and Desalinization of Saline Waters." U.S. Provisional Patent Application 62/945,638.

Kennedy, A.M. 1961. "The recovery of lithium and other metals from geothermal water at Wairakei." Proceedings of United Nations Conference on New Sources of Energy, Conf. 35/ G/56: 502-511.

Lee, J.M., and W. C. Bauman. 1978. "Recovery of lithium values from brines." U.S Patent No. $4,116,856$.

Lee, J. M., and W. C. Bauman. 1980. "Recovery of lithium values from brines." U.S. Patent No. 4,22 . 
Ling, L., V. G. Deshmane, M. P. Paranthaman, R. Bhave, B. A. Moyer, and S. Harrison. 2018. "Lithium Recovery from Aqueous Resources and Batteries: A Brief Review." Johnson Matthey Technology Review 62, no. 2: 161-176.

Liu, G., Z. Zhao, and A. Ghahreman. 2019. "Novel approaches for lithium extraction from saltlake brines: A review." Hydrometallurgy 187: 81-100.

Maimoni, A. 1982. "Minerals recovery from Salton Sea geothermal brines: A literature review and proposed cementation process." Geothermics 11, no. 4: 239-258.

Marston, C. R., and M. J. Garska. 2019. "Process for selective adsorption and recovery of lithium from natural and synthetic brines." U.S. Patent Application Publication US 2019 / 0256368 A1.

McKibben, M. A., and L. A. Hardie. 1997. “Ore-forming brines in active continental rifts.” In: Geochemistry of Hydrothermal Ore Deposits, 3rd ed. Barnes, H. L. (ed). Wiley Interscience: New York. p. 875-933.

Mroczek, E., G. Dedual, D. Graham, and L. Bacon. 2015. "Lithium extraction from Wairakei geothermal fluid using electrodialysis.” Proceedings World Geothermal Congress 2015 Melbourne, Australia.

Neupane, G., and D.S. Wendt. 2017. "Assessment of Mineral Resources in Geothermal Brines in the US." 42nd Workshop on Geothermal Reservoir Engineering. Stanford University.

Palmer, T.D. 1975 "Characteristics of geothermal wells located in the Salton Sea geothermal field, Imperial County, California.” Lawrence Livermore Laboratory UCRL-51976. https://www.osti.gov/servlets/purl/7356054

Paranthaman, M.P., L. Li, J.Q. Luo, T. Hoke, H. Ucar, B.A. Moyer, and S. Harrison. 2017. "Recovery of Lithium from Geothermal Brine with Lithium-Aluminum Layered Double Hydroxide Chloride Sorbents.” Environmental Science \& Technology 51: 13481-13486.

Renew, J., and T. Hansen. 2017. "Geothermal thermoelectric generation (G-TEG) with integrated temperature driven membrane distillation and novel manganese oxide for lithium extraction." United States. https://www.osti.gov/servlets/purl/1360976

S\&P Global Market Intelligence. 2019. "Lithium Sector: Production Costs Outlook." https://pages.marketintelligence.spglobal.com/lithium-sector-outlook-costs-and-marginsconfirmation-CD

Sanjuan, B., R. Millot, C. Innocent, C. Dezayes, J. Scheiber, and M. Brach. 2016. "Major geochemical characteristics of geothermal brines from the Upper Rhine Graben granitic basement with constraints on temperature and circulation." Chemical Geology 428: 27-47. 
Sanjuan, B., G. Negrel, M. Le Lous, E. Poulmarch, F. Gal, and P. Damy. 2020. "Main geochemical characteristics of the deep geothermal brine at Vendenheim (Alsace, France) with constraints on temperature and fluid circulation." World Geothermal Congress 2020 Reykjavik, Iceland.

Schmidt, A., F. Mestmäcker, L. Brückner, T. Elwert, and J. Strube. 2019. "Liquid-Liquid Extraction and Chromatography Process Routes for the Purification of Lithium." Materials Science Forum 959: 79-99.

Schultze, L.E., and D. J. Bauer. 1982. "Operation of a mineral recovery unit on brine from the Salton Sea Known Geothermal Resource Area.” Bureau of Mines Report of Investigations 8680.

Schultze, L.E., and D. J. Bauer. 1984. "Recovering lithium chloride from a geothermal brine." Bureau of Mines Report of Investigations 8883.

Simbol, Inc. 2015. Simbol Materials Lithium Extraction Operating Data from Elmore and Featherstone Geothermal Plants [data set]. Retrieved from https://dx.doi.org/10.15121/1196287.

Simmons, S.F., S. Kirby, P. Verplanck, and K. Kelley. 2018. "Strategic and Critical Elements in Produced Geothermal Fluids from Nevada and Utah." 43 ${ }^{\text {rd }}$ Workshop on Geothermal Reservoir Engineering, Stanford University.

Skinner, B. J., D. E. White, H. J. Rose, and R. E. Mays. 1967. "Sulfides associated with the Salton Sea Geothermal Brine.” Economic Geology 62, no. 3: 316-330.

Stringfellow, W.T., and P. F. Dobson. 2021. "Technology for Lithium Extraction in the Context of Hybrid Geothermal Power." $46^{\text {th }}$ Workshop on Geothermal Reservoir Engineering, Stanford University.

Ventura, S., S. Bhamidi, M. Hornbostel, A. Nagar, E. and Perea. 2016. "Selective Recovery of Metals from Geothermal Brines." Final Report DE-EE0006747.

Ventura, S., S. Bhamidi, and M. Hornbostel. 2018. "Selective recovery of lithium from brines." $43^{\text {rd }}$ Workshop on Geothermal Reservoir Engineering, Stanford University.

Ventura, S., S. Bhamidi, M. Hornbostel, and A. Nagar. 2020. "Selective Recovery of Lithium from Geothermal Brines." Final Project Report, California Energy Commission Energy Research and Development Division. CEC-500-2020-020.

Vulcan Energy Resources. 2020. "Positive PFS \& Maiden JORC Ore Reserve: Zero Carbon Lithium® Project.” ASX Release 15 January 2020.

Werner, H.H., 1970. "Contribution to the mineral extraction from supersaturated geothermal brines, Salton Sea area, California.” Geothermics 2: 1651-1655.

Williams, A.E., and M. A. McKibben. 1989. "A brine interface in the Salton Sea Geothermal System, California: Fluid geochemical and isotopic characteristics." Geochimica et Cosmochimica Acta 53, no. 8: 1905-1920. 
Xu, P., J. Hong, X. M. Qian, Z. W. Xu, H. Xia, X. C. Tao, Z. Z. Xu, and Q. Q. Ni. 2021. "Materials for lithium recovery from salt lake brine." Journal of Materials Science 56: 16-63.

Yang, S., G. Liu, J. Wang, L. Cui, and Y. Chen. 2019. "Recovery of lithium from alkaline brine by solvent extraction with functionalized ionic liquid." Fluid Phase Equilibria 493: 129-136.

Zhang, H., J. Hou, Y. Hu, P, Wang, R. Ou, L. Jiang, J.Z. Liu, B.D. Freeman, A.J. Hill, and H. Wang. 2018. "Ultrafast selective transport of alkali metal ions in metal organic frameworks with subnanometer pores." Science Advances 4, No. 2.

Zhao, X., H. Yang, Y. Wang, and Z. Sha. 2019. "Review on the electrochemical extraction of lithium from seawater/brine." Journal of Electroanalytical Chemistry 850.

Zukin, J. G., D. E. Hammond, T. Ku, and W. A. Elders. 1987. "Uranium-thorium series radionuclides in brines and reservoir rocks from two deep geothermal boreholes in the Salton Sea geothermal field, southeastern California." Geochimica et Cosmochimica Acta 51, no. 10: 27192731. 


\section{Appendix A. Lithium Extraction Process Details}

A.1 Simbol, Inc.

The intellectual property associated with Simbol's pilot testing of the extraction of lithium and other metals from Salton Sea brine is held by new owners as of this writing. A partnership called Terralithium (https://www.terralithium.com/) claims to hold Simbol and All American Lithium (doing business as Alger Alternative Energy) patents related to lithium extraction and related processes that were initially developed by Simbol.

Simbol focused on the recovery of lithium manganese, zinc, and potassium from pre-injection brines at the Elmore (CalEnergy) and Featherstone (EnergySource) power plants. Additional activities were directed toward improved management of silica and the generation of commercial products from silica management byproducts (Harrison 2014). The main process steps for lithium extraction were demonstrated at pilot scale: (1) silica management; (2) lithium extraction; (3) purification; (4) concentration; and (5) conversion into lithium hydroxide and lithium carbonate products.

\section{A.1.1 Silica Management}

Silica handling at Salton Sea power plants is accomplished with crystallizer-clarifier processes and chemical scale inhibition, and the downstream fluid (pre-injection) is the source brine for lithium extraction operations. Simbol (Harrison 2014) tested two novel silica removal techniques, one using a sorbent and the other using a precipitant. Silica removal via sorbents was problematic due to required large volumes of stripping solution and degradation of the sorbents. Silica removal using precipitants was problematic due to required large caustic volumes to maintain $\mathrm{pH}$ at optimal levels and, for some precipitants, lithium was also extracted. Of the two novel processes, silica removal via sorbent was deemed less costly and potentially economical for polishing solutions with low silica concentrations (Harrison 2014).

Current silica management at Salton Sea power plants produces a silica-iron filter cake, and Simbol also investigated ways to convert this into a commercial product, iron phosphate. Importantly, removal of $95 \%$ of arsenic was achieved by oxidizing $20 \%-30 \%$ of the iron between $\mathrm{pH}$ values of 3 and 4 before precipitation of silica-iron filter cake. During pilot testing at the Elmore and Featherstone power plants, more than $93 \%$ of silica and $98 \%$ percent of $\mathrm{Fe}$ (II) were removed as filter cake. Based on reporting by Harrison (2014), it is not explicitly stated whether silica was removed using the novel sorbent method or by the conventional crystallizerclarifier and chemical modification processes. The latter is expected based on the poor economics of the sorbent method and its unproven commercial process, along with reporting of removal of both silica and iron together.

\section{A.1.2 Lithium Extraction}

Simbol aimed to create new sorbents with higher capacities, longer lifetimes, lower costs, and with minimal co-extracted impurities (Harrison 2014). Several formulations and processing steps for sorbent production were tested. The sorbent chosen for development to commercial scale exhibited high capacity, low affinity for impurities, and production via a simple two-step process. Sorbent formulation and production are proprietary; however, Simbol patents (e.g., U.S. Patent $8,901,032$ ) indicate that the sorbents were developed from lithium-aluminum double 
hydroxide chloride (LDH). Paranthaman et al. (2017) provide details of development of LDH sorbents and use bench-scale tests to demonstrate high lithium recovery (91\%) and high separation factors for lithium versus sodium, potassium, and calcium.

A complete silica management and lithium extraction process was pilot-scale tested at the Elmore and Featherstone power plants in the Salton Sea KGRA after pilot-scale testing off-site using a surrogate brine. Two sorbents were tested at the Elmore plant, and a next generation sorbent was tested after the pilot test was moved to the Featherstone plant, where plans were to eventually scale to commercial operations.

At the Elmore plant, brine feed to the lithium extraction process was from injection pipelines at $105^{\circ} \mathrm{C}$ and $19 \mathrm{~L} / \mathrm{m}$. During 3,500 hours of operation, more than $95 \%$ of $\mathrm{LiCl}$ from the brine was recovered under optimal conditions (Harrison 2014).

After relocating to the Featherstone plant, purification and concentration steps were added to the process. Few details are provided, but the purification step removed trace metals from the $\mathrm{LiCl}$ solution produced during primary lithium extraction with specific mention of calcium and magnesium removal, while the concentration step produced a $35-40 \mathrm{wt} \% \mathrm{LiCl}$ solution (Harrison 2014). The pilot plant was operated for 9,000 hours.

\section{A.1.3 Conversion to Commercial Products}

Simbol developed a proprietary process for the conversion of concentrated $\mathrm{LiCl}$ solution into a 4 wt \% $\mathrm{LiOH}$ solution, which is evaporated, washed, and dried to produce $\mathrm{Li}(\mathrm{OH}) \cdot \mathrm{H}_{2} \mathrm{O}$. Simbol also developed a process to use $\mathrm{CO}_{2}$ from geothermal power operations to produce $\mathrm{Li}_{2} \mathrm{CO}_{3}$ from the $\mathrm{LiOH}$ solution; however, pilot scale demonstrations used to produce $\mathrm{Li}_{2} \mathrm{CO}_{3}$ also employed conventional reaction with $\mathrm{Na}_{2} \mathrm{CO}_{3}$ followed by filtering, washing, and drying to produce $99.9 \%$ pure $\mathrm{Li}_{2} \mathrm{CO}_{3}$.

The pilot plant converting concentrated $\mathrm{LiCl}$ solution to $\mathrm{LiOH}$ solution was operated for more than 1,000 hours using surrogate and geothermal-sourced LiCl solutions. Simbol's proprietary process successfully produced a $4 \mathrm{wt} \% \mathrm{LiOH}$ solution. Reaction of the $\mathrm{LiOH}$ solution produced a $\mathrm{Li}_{2} \mathrm{CO}_{3}$ slurry, which was filtered, washed, and dried to produce $26.3 \mathrm{~kg}$ of $99.9 \%$ pure $\mathrm{Li}_{2} \mathrm{CO}_{3}$ from $900 \mathrm{~L}$ of $4.5 \mathrm{wt} \% \mathrm{LiOH}$ (Harrison 2014). More than $95 \%$ of lithium was extracted from geothermal brine as lithium chloride, and conversion of lithium chloride to lithium hydroxide and lithium carbonate products showed yields $>90 \%$.

Though performance and cost details are not available, published chemical analyses of fluids from lithium extraction process steps are available (Simbol Inc. 2015). Table A-1 allows comparison of fluid compositions among post-flash brine, post-silica removal, and post-lithiumextraction process steps. These results show the successful concentration of lithium (high starting values and low post-extraction values) while limiting contamination by silica, sodium, potassium, calcium, and magnesium. 
Table A-1. Chemical Analyses of Fluids from Lithium Extraction Pilot Tests at Elmore and Featherstone Geothermal Power Plants, Salton Sea KGRA

\begin{tabular}{|c|c|c|c|c|c|c|c|}
\hline \multirow[b]{2}{*}{ Description } & \multicolumn{4}{|c|}{ Elmore (CalEnergy) } & \multicolumn{3}{|c|}{ Featherstone (EnergySource) } \\
\hline & \begin{tabular}{|c|} 
Post Flash Brine \\
Pre-injection
\end{tabular} & $\begin{array}{l}\text { Post silica } \\
\text { removal }\end{array}$ & $\begin{array}{c}\text { Post lithium extraction } \\
\text { column } 1\end{array}$ & $\begin{array}{c}\text { Post lithium extraction } \\
\text { column } 2\end{array}$ & \begin{tabular}{|c|} 
Post Flash Brine \\
Pre-injection2
\end{tabular} & $\begin{array}{l}\text { Post silica } \\
\text { removal }\end{array}$ & $\begin{array}{c}\text { Post lithium extraction } \\
\text { column } 1\end{array}$ \\
\hline TDS $\%$ & 31.3 & 30.4 & & & 28.9 & 26.5 & 0.0 \\
\hline $\mathrm{pH}$ & 4.7 & 5.1 & 5.0 & 5.2 & 4.9 & 5.5 & 5.5 \\
\hline $\mathrm{T}^{\circ} \mathrm{C}$ & 105 & 87 & 90 & 90 & 105 & 90 & 85 \\
\hline density $(\mathrm{g} / \mathrm{cm} 3)$ & 1.25 & 1.25 & 1.2 & 1.2 & 1.25 & 1.25 & 1.2 \\
\hline $\mathrm{SO} 4 \mathrm{ppm}$ & 127.3 & 81.6 & 46.3 & 46.3 & & & \\
\hline F ppm & 23.8 & 10.7 & 0.0 & 0.0 & & & \\
\hline Ag ppm & 0.3 & 0.3 & & 0.2 & 0.8 & 0.8 & 0.2 \\
\hline Al ppm & 3.3 & 3.2 & & 2.2 & 20.2 & 20.2 & 1.3 \\
\hline As ppm & 13.1 & 0.0 & 0.0 & 0.0 & 11.4 & 7.1 & 0.6 \\
\hline B ppm & 394.4 & 390.9 & 382.1 & 367.0 & 501.0 & 438.3 & 398.1 \\
\hline Ba ppm & 196.6 & 143.5 & 85.2 & 84.5 & 174.5 & 97.1 & 87.2 \\
\hline Be ppm & 0.0 & 0.0 & 0.0 & 0.0 & 0.3 & 0.3 & 0.0 \\
\hline Ca ppm & 28477.5 & 32401.2 & 31670.3 & 29969.5 & 39642.9 & 35496.2 & 38085.4 \\
\hline Cd ppm & 2.0 & 1.7 & & 0.5 & 4.0 & 4.0 & 2.6 \\
\hline Co ppm & 0.0 & 0.0 & 0.0 & 0.0 & 10.1 & 10.1 & 0.6 \\
\hline Cr ppm & 0.0 & 0.0 & 0.0 & 0.0 & 2.0 & 2.0 & 0.1 \\
\hline Cu ppm & 2.8 & 2.8 & & 2.3 & 5.6 & 5.3 & 3.9 \\
\hline Fe ppm & 1652.4 & 18.6 & 9.9 & 6.0 & 830.0 & 10.1 & 1.4 \\
\hline $\mathrm{K} \mathrm{ppm}$ & 18264.8 & 18218.9 & 18215.0 & 18000.0 & 22657.1 & 20723.1 & 20378.2 \\
\hline Li ppm & 250.4 & 247.8 & 87.0 & 112.7 & 265.6 & 203.5 & 28.7 \\
\hline Mg ppm & 41.0 & 64.0 & & 46.4 & 67.6 & 68.5 & 61.0 \\
\hline Mn ppm & 1344.9 & 1310.6 & 1299.9 & 1216.2 & 1954.3 & 1728.8 & 1531.8 \\
\hline Mo ppm & 0.0 & 0.0 & 0.0 & 0.0 & 10.1 & 10.1 & 2.6 \\
\hline Na ppm & 60883.2 & 59878.5 & 57282.3 & 54825.0 & 74500.0 & 66742.3 & 65215.4 \\
\hline Ni ppm & 0.0 & 0.0 & 0.0 & 0.0 & 0.6 & 0.6 & 0.1 \\
\hline $\mathrm{Pb}$ ppm & 91.4 & 76.6 & 71.3 & 70.4 & 134.6 & 112.4 & 105.9 \\
\hline Sb ppm & 0.0 & 0.0 & 0.0 & 0.0 & 8.1 & 8.1 & 0.5 \\
\hline Se ppm & 0.4 & 0.6 & & 0.2 & 9.1 & 9.1 & 1.5 \\
\hline Si ppm & 52.1 & 4.3 & 3.5 & 3.4 & 43.6 & 4.5 & 2.9 \\
\hline Sr ppm & 522.2 & 521.1 & 511.4 & 481.0 & 593.7 & 520.5 & 521.2 \\
\hline Т ppm & 1.0 & 1.0 & & 0.6 & 3.0 & 3.1 & 1.7 \\
\hline V ppm & 0.0 & 0.0 & 0.0 & 0.0 & 0.7 & 0.8 & 0.3 \\
\hline Zn ppm & 462.3 & 462.7 & 464.4 & 443.4 & 614.7 & 517.6 & 577.9 \\
\hline
\end{tabular}

\section{A.2 SRI International}

SRI International studied lithium extraction from geothermal brines with support from DOE and the California Energy Commission (Ventura et al. 2016, 2018, 2020). Ventura et al. (2016) reported on the development of ion exchange resins produced using metal-ion imprinted polymer beads for extraction of lithium and manganese. The lithium-ion imprinted polymers were prepared by suspension polymerization of a mixture comprising lithium chelate monomer, comonomer, ethylene glycol dimethacrylate as a crosslinking agent, porogen solvent, and radical initiator azobisisobutyronitrile. Several polymer compositions were created by varying the amount of crosslinking agent and type of co-monomer. The polymer comprised 100- to 150micron diameter beads formed into $\geq 300$-micron diameter agglomerates. After beads were washed and dried, bound lithium was removed with dilute $\mathrm{HCl}$. Thermal testing showed that the polymers were stable at up to $243^{\circ} \mathrm{C}$. A range of lithium-ion-imprinted polymer compositions were tested at temperatures of $45^{\circ} \mathrm{C}, 75^{\circ} \mathrm{C}$, and $100^{\circ} \mathrm{C}$, and lithium uptake capacity was found to be up to $2.8 \mathrm{mg} \mathrm{Li} / \mathrm{g}$ sorbent at $45^{\circ} \mathrm{C}$. In synthetic brines $\left(412 \mathrm{mg} / \mathrm{kg} \mathrm{Li}{ }^{+}, 405 \mathrm{mg} / \mathrm{kg} \mathrm{Na}{ }^{+}, 435\right.$ $\mathrm{mg} / \mathrm{kg} \mathrm{K}^{+}$), metal-ion imprinted polymer bound almost exclusively with lithium, and flowthrough, packed-bed experiments showed lithium separation efficiency of $95 \%$. In higher salinity $\mathrm{Na}$ and K brines (Li $360 \mathrm{mg} / \mathrm{kg}$, Na 10,000 mg/kg, K 3,000 mg/kg), separation factors of lithium versus sodium and potassium ranged from 2.3-4.5, and flow-through, packed-bed experiments showed lithium separation efficiency of 30\%. When tested with $\mathrm{Ca}$ and $\mathrm{Mg}$ brines $(400 \mathrm{mg} / \mathrm{kg}$ $\mathrm{Li}^{+}, 400 \mathrm{mg} / \mathrm{kg} \mathrm{Mg}^{++}, 265 \mathrm{mg} / \mathrm{kg} \mathrm{Ca}{ }^{++}$), the metal-ion imprinted polymers were found to have 
lithium separation factors $<1$, indicating the need to remove $\mathrm{Ca}^{++}$and $\mathrm{Mg}^{++}$prior to lithium extraction with the tested metal-ion polymers. In packed-bed experiments, $\mathrm{Li}^{+}$uptake through three $45^{\circ} \mathrm{C}$ cycles and two $75^{\circ} \mathrm{C}$ cycles showed a stable, average uptake of $0.92 \mathrm{mg} \mathrm{Li} / \mathrm{g}$ sorbent. With respect to lithium extraction, Ventura et al. (2016) found that the sorbent selectivity and capacity needed to be increased, especially for use with higher salinity brines like those at the Salton Sea KGRA.

Building on the work of Ventura et al. (2016), Ventura et al. $(2018,2020)$ focused on improving sorbent characteristics for lithium extraction with a novel nanocomposite sorbent made of hydrated manganese oxide lithium-ion sieve nanoparticles and lithium-imprinted polymer formed into beads, which were tested in column experiments with brines containing high concentrations of alkali and alkaline earth metals. Lithium capacity and selectivity were improved from earlier sorbent designs, with capacities as high as $16.2 \mathrm{mg} \mathrm{Li} / \mathrm{g}$ sorbent and high separation coefficients with $\mathrm{Na}^{+}, \mathrm{K}^{+}, \mathrm{Ca}^{++}$, and $\mathrm{Mg}^{++}$. Tested against a synthetic brine with $\mathrm{Li}$, $\mathrm{Na}, \mathrm{K}$, and Ca at Salton Sea concentrations $(377 \mathrm{mg} / \mathrm{L} \mathrm{Li}, 57,777 \mathrm{mg} / \mathrm{L}$ of Na, $14,448 \mathrm{mg} / \mathrm{L}$ of $\mathrm{K}$, and $26,766 \mathrm{mg} / \mathrm{L}$ of $\mathrm{Ca}$ ), sorbent lithium capacity was up to $11 \mathrm{mg} \mathrm{Li} / \mathrm{g}$ sorbent and similarly displayed high separation coefficients. In the final phase of their research, Ventura et al. (2020) further refined sorbent composition and the lithium extraction process and proved their efficacy with a Salton Sea geothermal brine in a $100-\mathrm{h}, \sim 635 \mathrm{~cm}^{3} / \mathrm{h}$, packed-bed, experiment that recovered $90 \%$ of lithium from the brine with multiple sorbent regeneration cycles. Prior to the experiment, the brine was pre-treated with addition of $\mathrm{NaOH}$ to raise the $\mathrm{pH}$ to 8-9, after which a precipitate was removed from the brine via precipitation. The precipitate was analyzed by Xray diffraction and found to contain aluminum, manganese, iron, zinc, and small amounts of magnesium and calcium, while the treated brine contained $319 \mathrm{mg} / \mathrm{L} \mathrm{Li}, 77,173 \mathrm{mg} / \mathrm{L} \mathrm{Na}, 27,409$ $\mathrm{mg} / \mathrm{L} \mathrm{K}, 42,831 \mathrm{mg} / \mathrm{L} \mathrm{Ca}$, and $694 \mathrm{mg} / \mathrm{L} \mathrm{Sr}$. Additionally, a sorbent regeneration process was developed using carbon dioxide to concentrate lithium bicarbonate that is readily converted to high purity lithium carbonate. A range of temperatures and $\mathrm{CO}_{2}$ pressures were tested to optimize desorption of lithium from the sorbent. An alternative to $\mathrm{HCl}$ for sorbent regeneration was deemed important to minimize deleterious effects on the hydrated manganese oxide due to $\mathrm{Mn}$ solubility in $\mathrm{HCl}$. They noted that next steps required scaling up the process, longer duration testing to assess sorbent durability, and evaluation of specific location and operation conditions that might require additional pre-treatment of geothermal brine before lithium extraction. Based on bench-scale experimental results, Ventura et al. (2020) estimate a production cost of $\$ 3,845 / \mathrm{mt} \mathrm{Li}_{2} \mathrm{CO}_{3}$ using their sorbents and extraction process based on a 50-MW Salton Sea power plant with $6,000 \mathrm{gpm}$ throughput and $400 \mathrm{mg} / \mathrm{kg} \mathrm{Li}$ in brine.

\section{A.3 Southern Research, Novus Energy Technologies, Carus Corporation, and Applied Membrane Technology Inc.}

DOE funding supported a consortium of companies that combined expertise in various components of a system to extract lithium from geothermal brine. Renew and Hansen (2017) report results of the project that investigated a modular technology approach with components focused on silica removal, nanofiltration, membrane distillation, Mn-oxide sorbent for lithium recovery, and thermo-electric generation. Notably, the synthetic brines studied have significantly lower concentrations than Salton Sea brines with respect to all reported species. A process schematic is shown in Figure A-1. 


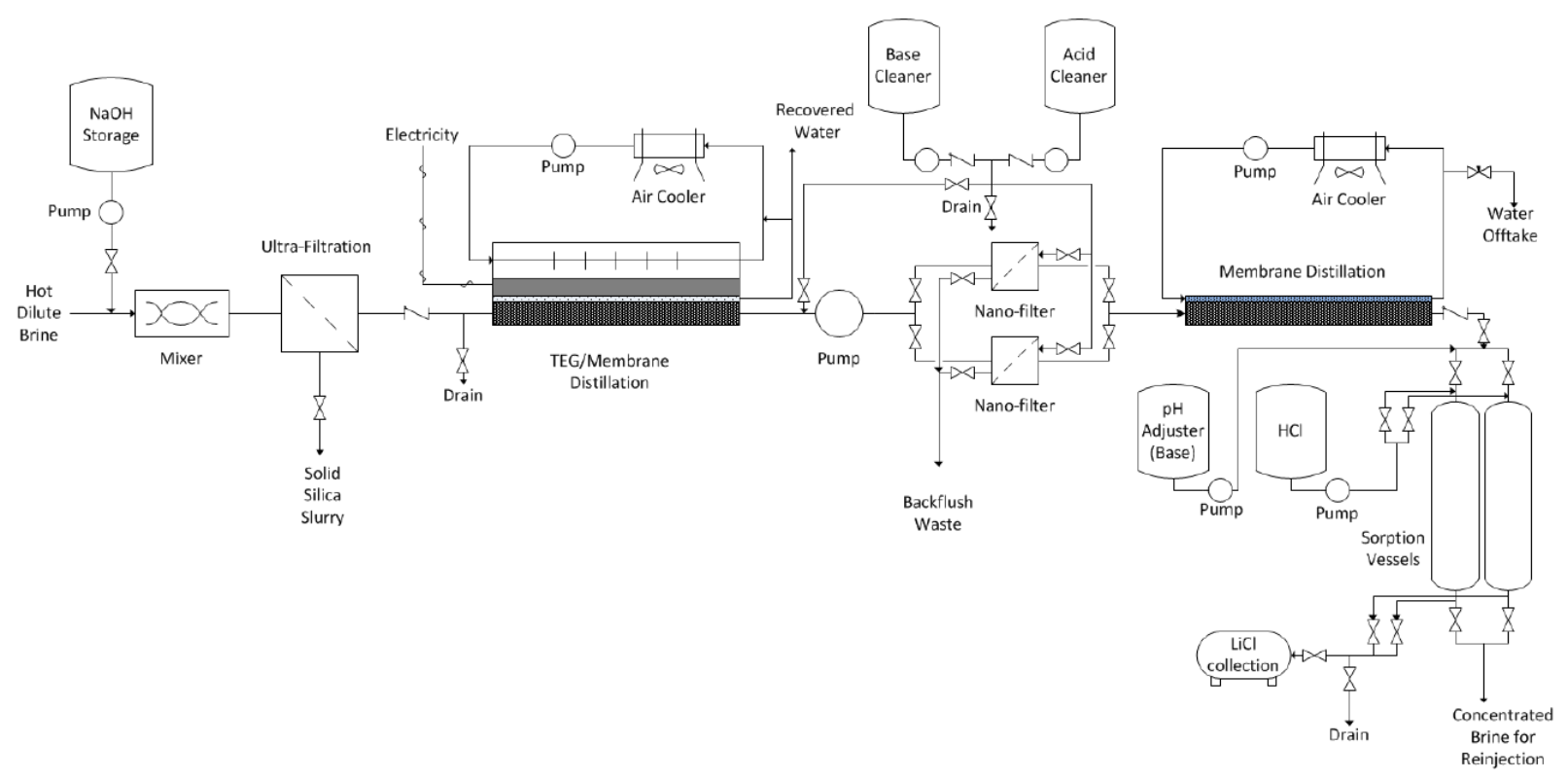

Figure A-1. Schematic representation of the lithium extraction process proposed by Renew and Hansen (2017)

Silica is removed using $\mathrm{NaOH}$ and $\mathrm{FeCl}_{3}$ addition to raise $\mathrm{pH}$ and drive silica precipitation. The first of a two-stage membrane distillation process incorporates a high temperature membrane capable of operations at up to $150^{\circ} \mathrm{C}$ coupled with a thermal-electric generator that uses the heat energy from the membrane permeate to produce electricity. The next step removes $\mathrm{Ca}^{2+}$ and $\mathrm{Mg}^{2+}$ via nanofiltration followed by a second membrane distillation. Concentrated brine is contacted with Mn-oxide sorbent to extract lithium. After loading, lithium is stripped from the sorbent using $\mathrm{HCl}$ (Renew and Hansen 2017).

\section{A.4 Vulcan Energy Resources}

Vulcan Energy Resources proposes to develop hybrid geothermal power generation and lithium extraction in the Upper Rhine Valley of southwest Germany. The potential for geothermal power generation is known from existing power plants and exploration, while the potential for lithium extraction is indicated by lithium concentration in geothermal brine up to $210 \mathrm{mg} / \mathrm{kg}$ lithium (Sanjuan et al., 2016). Bench-scale DLE studies with two commercially available sorbents using Upper Rhine Valley geothermal brine showed Li recovery rates of more than $90 \%$. Upper Rhine Valley brines most amenable to lithium extraction have chemistries approximately 150-200 $\mathrm{mg} / \mathrm{kg}$ lithium, 30,000 mg/kg sodium, 2,000 mg/kg potassium, $6,000 \mathrm{mg} / \mathrm{kg}$ calcium, and 400 $\mathrm{mg} / \mathrm{kg}$ magnesium from reservoirs measured up to $200^{\circ} \mathrm{C}$ and with geothermometry indicating $225^{\circ} \mathrm{C}$ (Sanjuan et al. 2016).

The DLE process comprises brine pre-treatment, brine purification, extraction of lithium via a sorbent, and concentration of lithium chloride solution using renewable heat from the geothermal plant before it is sent to the conversion plant. Barren brine is treated and directed to wells for reinjection into the geothermal reservoir. At the conversion plant, the $\mathrm{LiCl}$ concentrated solution is further purified before electrolytic conversion of the $\mathrm{LiCl}$ solution to lithium hydroxide $(\mathrm{LiOH})$ solution, chlorine, and hydrogen gas. Hydrogen and chlorine gas are used to generate 
$\mathrm{HCl}$, and the lithium hydroxide solution is further purified before crystallization of LHM from the LiOH solution. Figure A-2 shows a schematic of Vulcan Energy Resources proposed process.

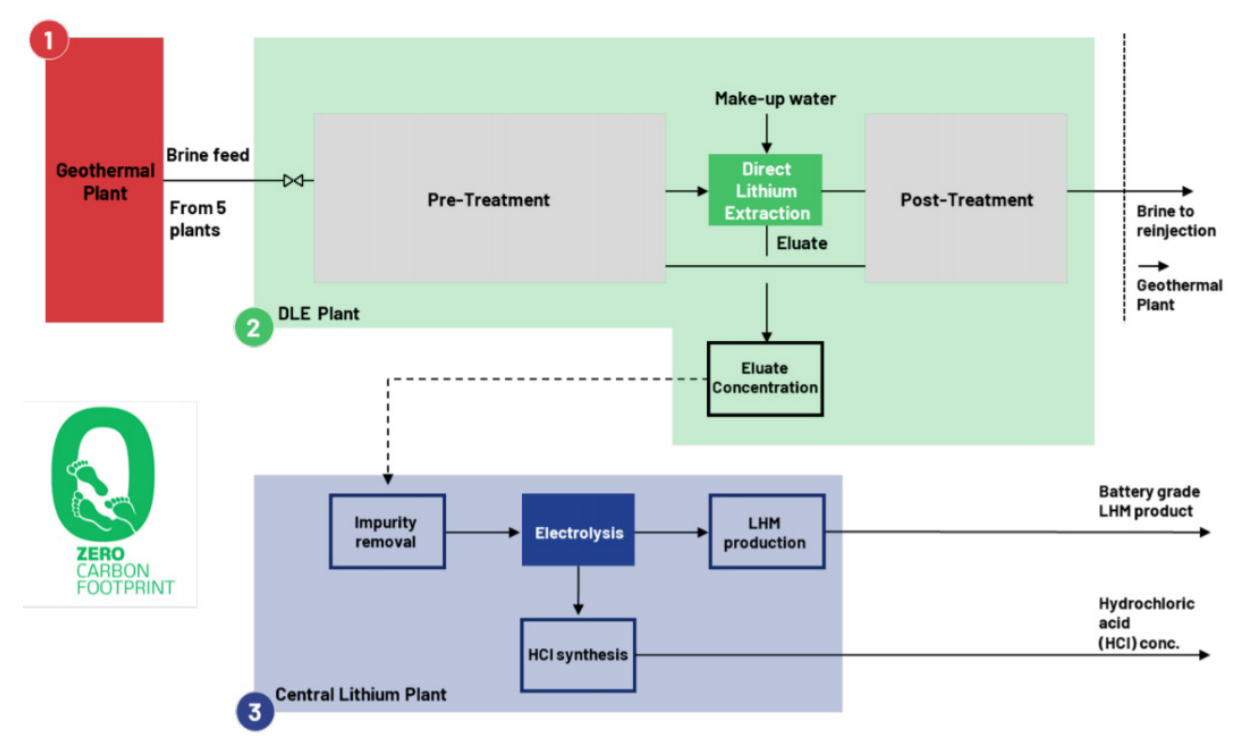

Figure A-2. Vulcan Energy Resources' proposed hybrid geothermal and lithium extraction project

\section{A.5 Standard Lithium}

Standard Lithium began testing a lithium extraction demonstration plant in late 2020 using the tail brine from Lanxess bromine extraction operations in Arkansas, and they plan to scale up to a $20,900 \mathrm{mt} / \mathrm{yr}$ commercial operation. The tail brine contains an average lithium concentration of $168 \mathrm{mg} / \mathrm{L}$, and the brine resource contains 3,140,000 $\mathrm{mt} \mathrm{LCE}$.

Most publicly available details are from earlier bench- and mini-pilot-scale testing $(240 \mathrm{~L} / \mathrm{h}$ for three weeks). Lanxess tail brine, exiting the bromine extraction process at $70^{\circ} \mathrm{C}$, did not require any pre-treatment during testing though the process schematic (Figure A-3) includes "brine preparation" that at a minimum is likely to include a filtration step. Fine, inorganic, ion-exchange sorbent is mixed with the brine in loading reactors with sodium hydroxide or ammonia added as needed to maintain a $\mathrm{pH}$ of 7-7.8. Time to adsorb lithium in the loading reactor is less than one hour at ambient temperature. Loaded sorbent forms a slurry that is separated from barren brine using a combination of membrane filtration and counter-current decantation and washed with water to remove any remaining brine or residual solids. Additional thickening of the washed and loaded sorbent is possible via gravity settling in thickener/clarifier tanks, and vacuum filtration was also identified as a means for dewatering. The loaded adsorbent slurry is stripped with dilute $\mathrm{HCl}$ in elution reactors, regenerating the sorbent before it is returned to the loading reactor. After stripping, the concentrated $\mathrm{LiCl}$ solution is purified to remove traces of alkali and alkaline earth metals via a stepped process of sodium hydroxide addition, sodium carbonate addition, and membrane filtration. Final polishing is achieved via ion-exchange before the concentrated $\mathrm{LiCl}$ solution is ready for carbonation. With addition of $\mathrm{CO}_{2}$ and heat, the solubility of lithium carbonate is decreased to promote precipitation, and precipitated $\mathrm{Li}_{2} \mathrm{CO}_{3}$ is removed via filtration. Multiple, additional purification steps followed by drying, sizing, and packing generate the final $\mathrm{Li}_{2} \mathrm{CO}_{3}$ product. Standard Lithium is also working with researchers at the University of 
British Columbia to improve and simplify $\mathrm{Li}_{2} \mathrm{CO}_{3}$ precipitation through a continuous crystallization process (Standard Lithium 2019).

In late 2020, Standard Lithium announced that they had successfully produced concentrated $\mathrm{LiCl}$ solution from their demonstration plant in Arkansas operating under optimized and refined processes summarized above and processing $50 \mathrm{gpm}$ of brine from the Lanxess South Plant. The $\mathrm{LiCl}$ solution was further concentrated via reverse osmosis before using the developed continuous crystallization process to produce $99.9 \%$ pure $\mathrm{Li}_{2} \mathrm{CO}_{3}$.

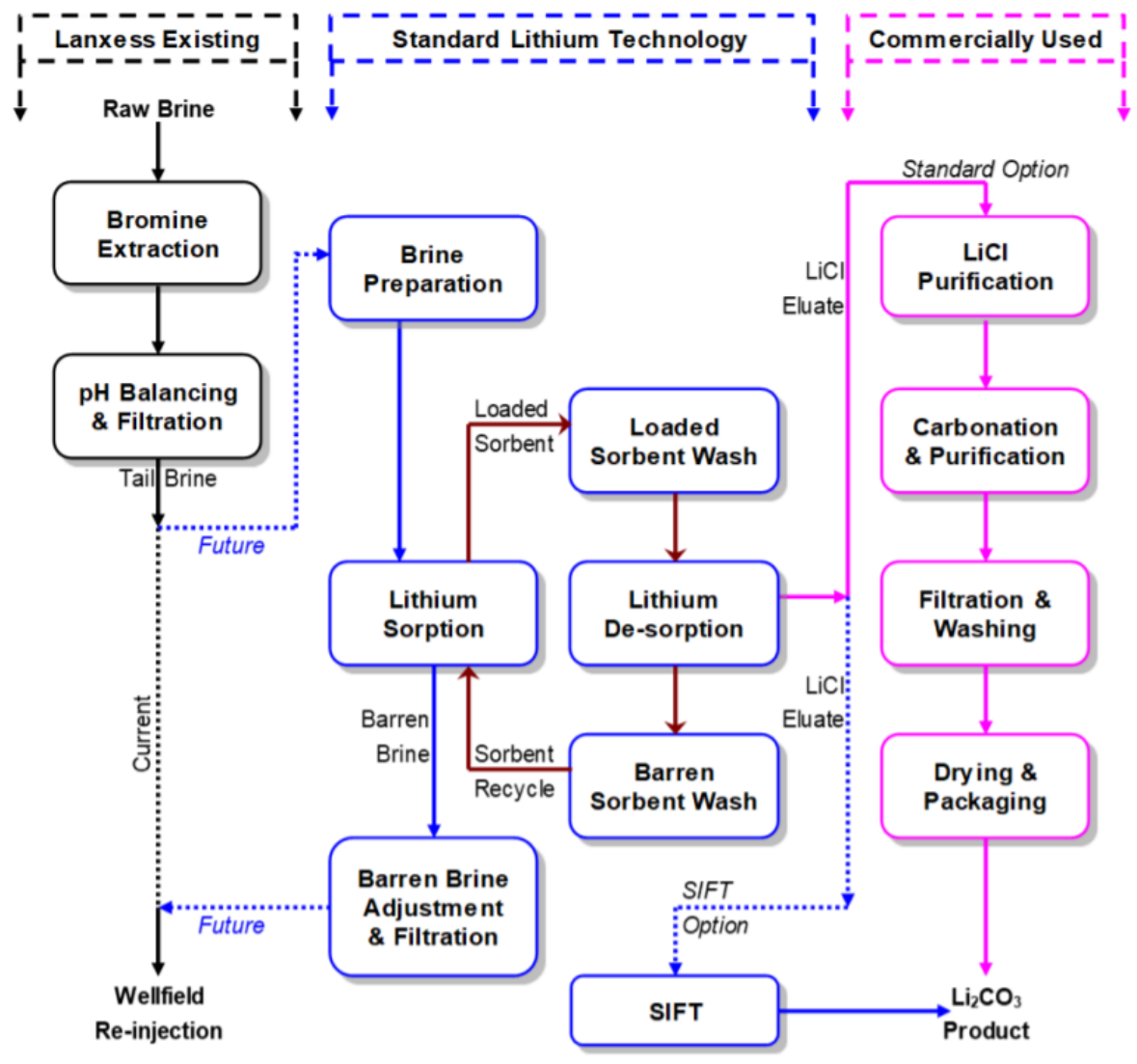

Figure A-3. Schematic representation of Standard Lithium's lithium extraction process

Standard Lithium (2019)

\section{A.6 E3 Metals Corp}

E3 Metals proposes to extract lithium from oilfield brine of the Leduc Formation in Alberta, Canada. The average lithium concentration is $74.6 \mathrm{mg} / \mathrm{L}$ with a resource estimated at 2.2 million $\mathrm{mt} \mathrm{LCE}$. After pre-treatment to remove entrained natural gas and $\mathrm{H}_{2} \mathrm{~S}$, lithium in the brine is concentrated using E3 Metals' ion-exchange sorbent material in a counter-current resin-in-pulp style circuit using stirred reactor tanks. The 1-2 mm diameter sorbent particles adsorb lithium from brine in which the anion is mostly chloride. The sorbent is eluted with dilute sulfuric acid during which lithium is concentrated to approximately $870 \mathrm{mg} / 1 \mathrm{Li}^{+}$using the anolyte recycled from the electrolysis circuit. Following the ion-exchange lithium extraction, most of the remaining species (calcium, magnesium, strontium, manganese, and boron) are removed by precipitation as hydroxides and carbonates. The $\mathrm{pH}$ of the $\mathrm{Li}^{+}$stream is lowered to prevent 
membrane fouling, and the lithium-enriched eluate is further concentrated by reverse osmosis before the remaining divalent ions $\left(\mathrm{Ca}^{+}\right.$and $\left.\mathrm{Mg}^{+}\right)$are removed in a secondary ion-exchange circuit. The purified brine, containing mostly $\mathrm{Li}^{+}, \mathrm{K}^{+}$and $\mathrm{Na}^{+}$cations, is suitable for electrolysis and crystallization to form $\mathrm{LiOH} \cdot \mathrm{H}_{2} \mathrm{O}$, while water removed from the brine prior to electrolysis can be used as make-up water for lithium processing. The electrolysis process forms a weak sulfuric acid stream, which is recycled to the elution stage, reducing the need for purchase of large quantities of reagent. A schematic representation of the process is shown in Figure A-4.

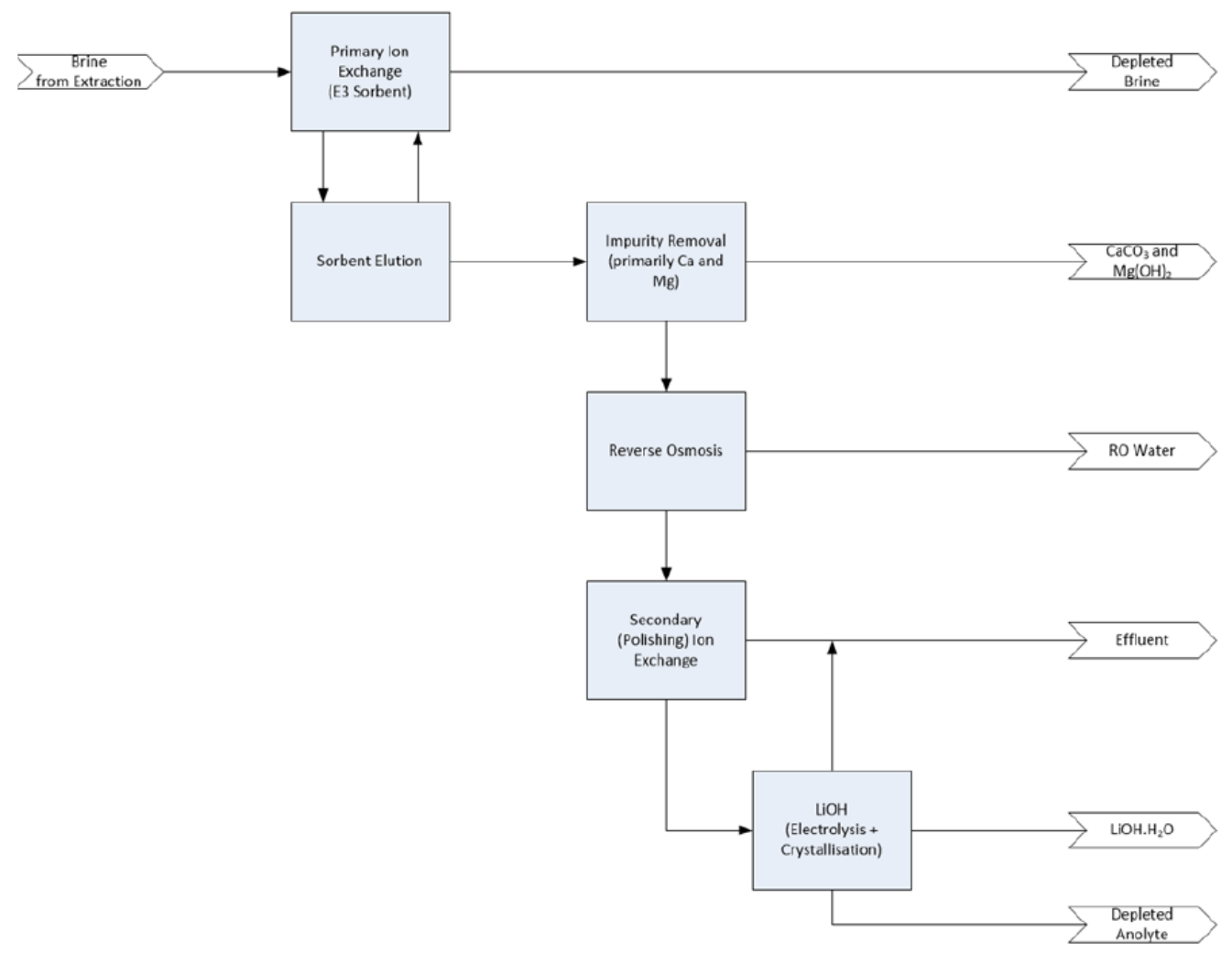
Figure A-4. Schematic representation and process flow chart of E3 Metal Corp.'s lithium extraction
process

E3 Metals Corp. (2020)

\section{A.7 Anson Resources}

Anson Resources Paradox Basin project is located in Utah and consists of three phases of development (Anson Resources 2020). Phase 1 is focused on bromine extraction. Phase 2 will construct and operate a pilot-scale lithium extraction plant with results informing the final process design for a commercial-scale lithium extraction operation in Phase 3. The PEA for Phase 3 was retracted soon after it was released because of its significant reliance on inferred resources. Despite that, the information about the proposed lithium extraction process and estimates of costs remain valid, separate from the issue of overall project viability.

The bromine-lithium brine is hosted in sedimentary units $\sim 1,900 \mathrm{~m}$ below surface that are intersected by historic hydrocarbon wells. The brine is estimated to contain 192,000 mt LCE with lithium concentrations up to $253 \mathrm{mg} / \mathrm{L}$. A single-pass, ion-exchange process will be tested 
in Phase 2 to produce a lithium-enriched eluate to feed a conversion process to produce $\mathrm{Li}_{2} \mathrm{CO}_{3}$ and potentially $\mathrm{LiOH} \cdot \mathrm{H}_{2} \mathrm{O}$. In Phase 3, design optimization developed during pilot testing will be scaled up to a 15,000-mt-per-year LCE operation.

The steps for lithium extraction are shown in Figure A-5. After bromine extraction, the brine is pre-treated to remove impurities before the ion-exchange process generates a lithium-enriched eluate. The concentrated $\mathrm{LiCl}$ eluate is converted to $\mathrm{LiOH}$ via electrolysis, during which addition of sodium chloride produces chlorine gas that is used to generate dilute $\mathrm{HCl}$ for stripping of the ion-exchange sorbent. Evaporation, crystallization, and drying complete production of $\mathrm{LiOH} \cdot \mathrm{H}_{2} \mathrm{O}$. The $\mathrm{LiOH}$ solution can be carbonated, filtered, dried, and micronized to produce $\mathrm{Li}_{2} \mathrm{CO}_{3}$.

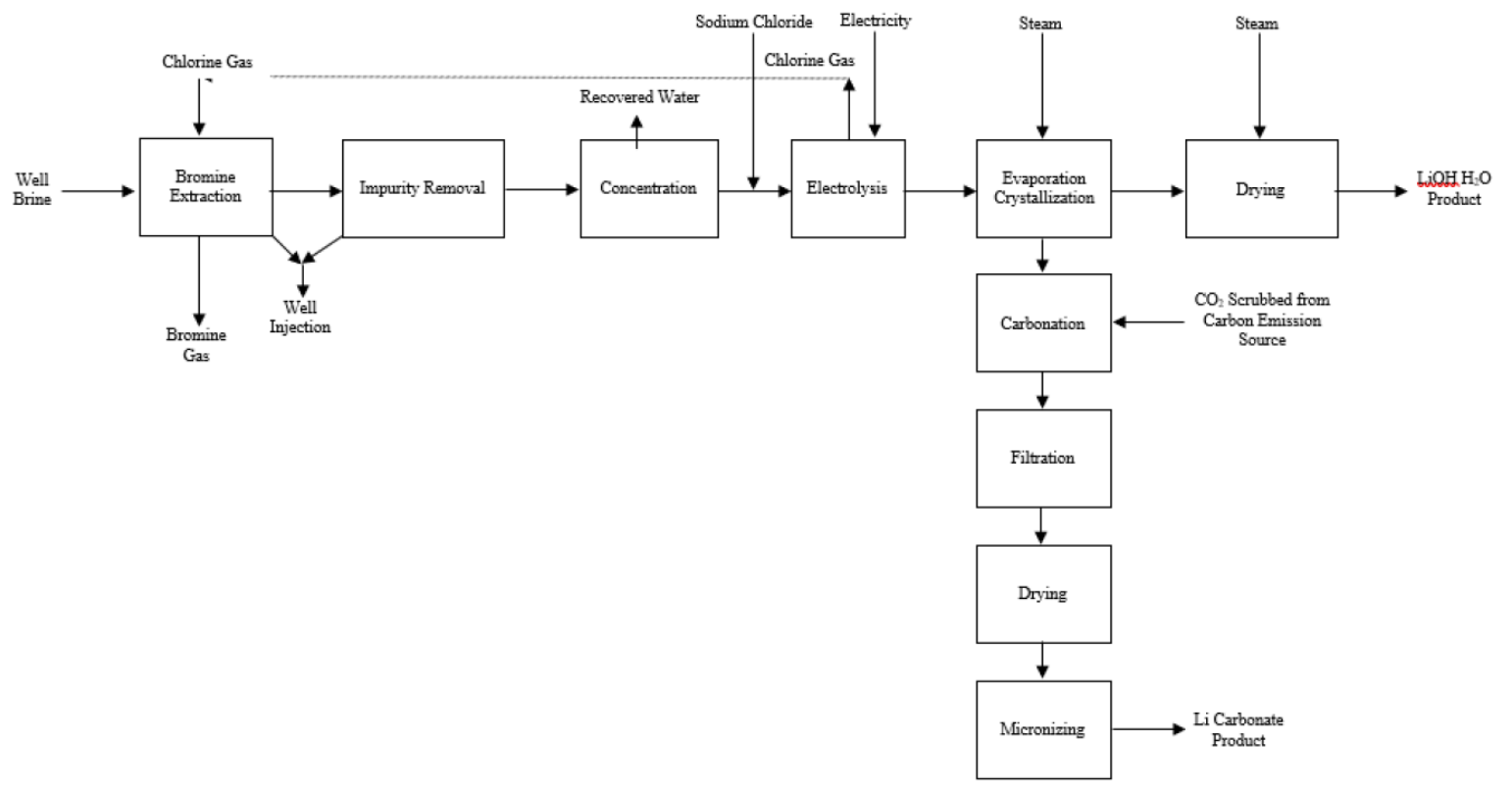

Figure A-5. Schematic diagram of Anson's proposed bromine and lithium extraction process

Anson Resources (2020)

\section{A.8 Pure Energy Minerals}

Pure Energy Minerals Clayton Valley project is in Nevada where they plan to produce 11,500 $\mathrm{mt}$ per year of lithium hydroxide monohydrate $\left(\mathrm{LiOH} \cdot \mathrm{H}_{2} \mathrm{O}\right.$; LHM) from brines containing up to 221 $\mathrm{mg} / \mathrm{L}$ lithium that comprise a resource of 247,000 $\mathrm{mt}$ of LHM in saturated basin sediments from $\sim 150-1,000 \mathrm{~m}$ below surface. Tenova has developed a novel extraction process that was confirmed with a mini-pilot test using a synthetic brine to match the physical and chemical properties of naturally occurring Clayton Valley brines. The process is schematically shown in Figure A-6. 


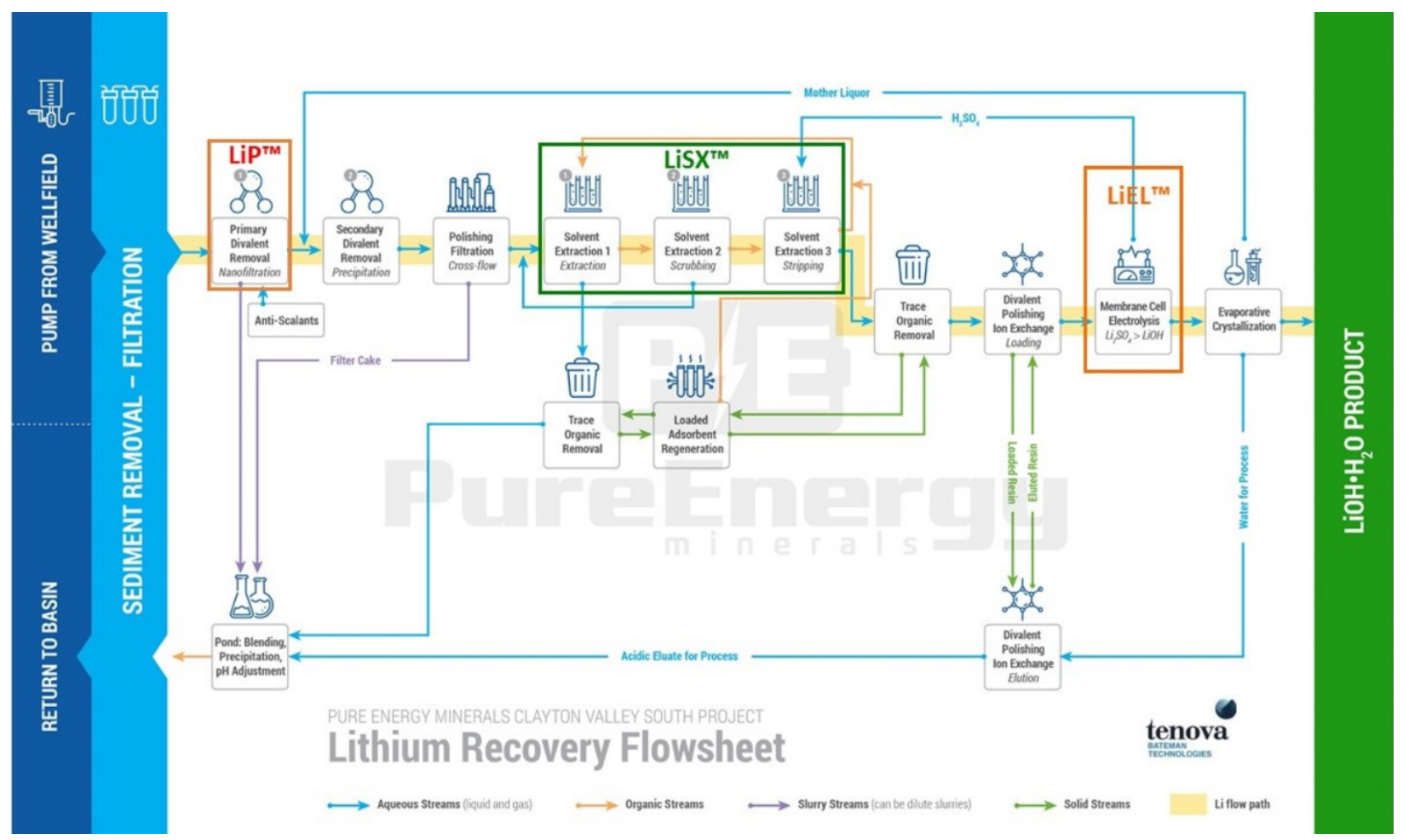

Figure A-6. Lithium recovery flowsheet for Pure Energy Minerals' Clayton Valley project

Pure Energy Minerals (2018)

The pre-treatment is designed to remove divalent ions, $\mathrm{Ca}^{2+}$ and $\mathrm{Mg}^{2+}$, by nanofiltration, precipitate the remaining $\mathrm{Ca}^{2+}$ and $\mathrm{Mg}^{2+}$ with $\mathrm{pH}$ modification, and remove the precipitates by clarification and/or filtration. The solvent extraction process is selective for lithium versus monovalent cations, so divalent cations must be removed prior to solvent extraction. The solvent extraction process uses an organic phase with extractants that selectively bind with lithium ions. The lithium-loaded organic phase is stripped with sulfuric acid. After solvent extraction, the $\mathrm{LiSO}_{4}$ solution is polished via ion exchange before an electrolysis process that transforms it into a LiOH solution. The final LHM product is generated from evaporative crystallization to remove free water.

\section{A.9 Lake Resources}

Lake Resources Kachi project is in Catamarca, Argentina. The salar brine indicated resource comprises 1 million tons LCE with a concentration of $250 \mathrm{mg} / \mathrm{L}$ lithium contained in saturated sediments that extend to $880 \mathrm{~m}$ below surface. The project aims to produce $25,500 \mathrm{mt}$ per year of lithium carbonate with DLE via ion exchange (Figure A-7), producing an LiCl-enriched eluate that is converted to $\mathrm{Li}_{2} \mathrm{CO}_{3}$ with addition of $\mathrm{Na}_{2} \mathrm{CO}_{3}$. After brine is pumped to the surface, it is filtered to remove solids prior to entering the ion-exchange process, where a proprietary ionexchange sorbent extracts $\mathrm{Li}+$ from the brine by exchanging for an $\mathrm{H}+$. The lithium-loaded sorbent is stripped with dilute $\mathrm{HCl}$ to produce an $\mathrm{LiCl}$-enriched eluate, which is further concentrated via reverse osmosis. Addition of $\mathrm{Na}_{2} \mathrm{CO}_{3}$ precipitates $\mathrm{Li}_{2} \mathrm{CO}_{3}$ that is separated via filtration, dried, and packaged (Lake Resources 2020). The project also considers onsite generation of reagents with $\mathrm{NaCl}$ and water converted to $\mathrm{NaOH}$, hydrogen gas, and chlorine gas 
via electrolysis (reagent regeneration, Figure A-7) with furnace heating used to form gaseous $\mathrm{HCl}$.

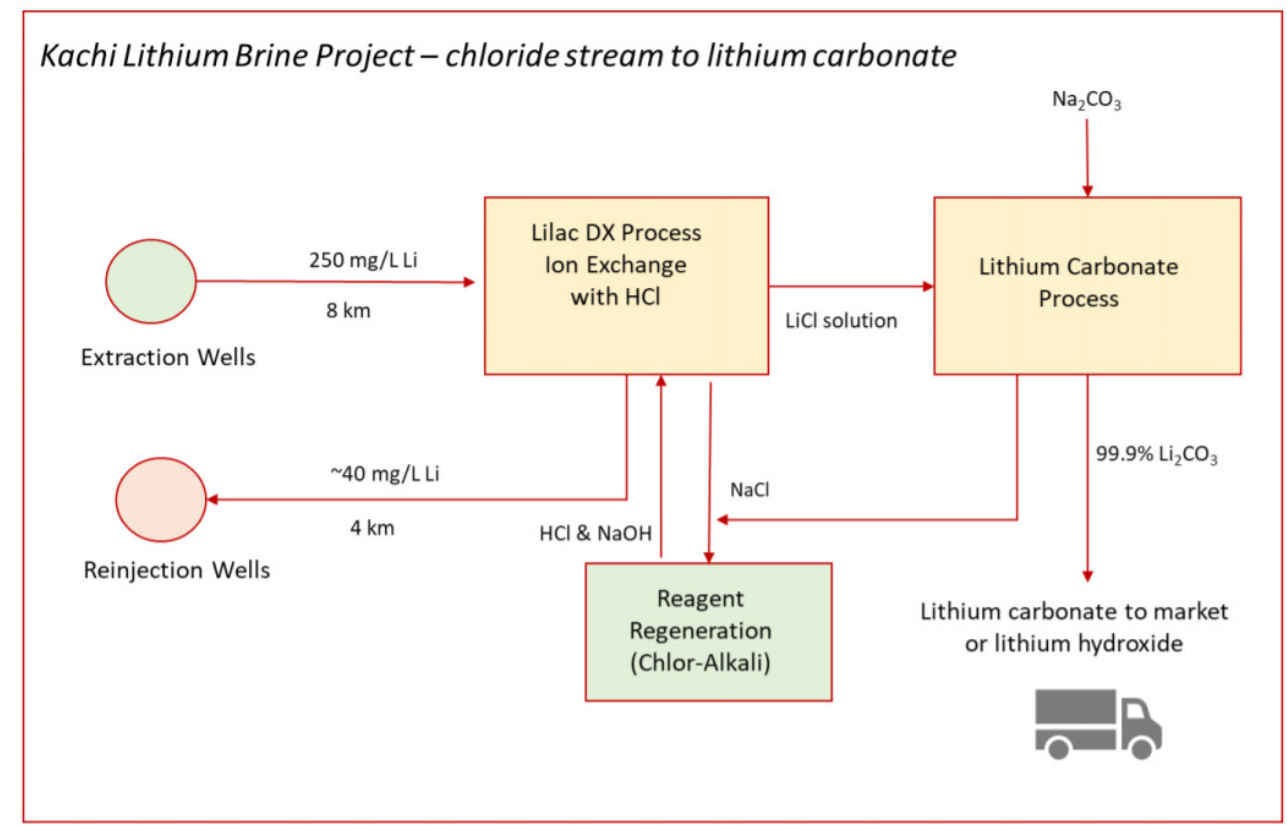

Figure A-7. Schematic representation of Lake Resources proposed ion-exchange process to extract lithium from salar brine 